\title{
Cellular limitation of enzymatic capacity explains glutamine addiction in cancers
}

Johan Gustafsson ${ }^{1,2}$, Fariba Roshanzamir ${ }^{1}$, Anders Hagnestål ${ }^{3}$, Jonathan L. Robinson ${ }^{1,4}$, Jens Nielsen ${ }^{1,2,4, *}$

${ }^{1}$ Department of Biology and Biological Engineering, Chalmers University of Technology, Gothenburg, Sweden.

${ }^{2}$ Wallenberg Center for Protein Research, Chalmers University of Technology, Gothenburg, Sweden.

${ }^{3}$ Hagnesia $A B$, Hindås, Sweden

${ }^{4}$ Biolnnovation Institute, Copenhagen, Denmark

* Corresponding author

E-mail: nielsenj@chalmers.se 


\section{Abstract}

Metabolism within the tumor microenvironment, where a complex mixture of different cell types resides in a nutrient-deprived surrounding, is not fully understood due to difficulties in measuring metabolic fluxes and exchange of metabolites between different cell types in vivo. Genome-scale metabolic modeling enables estimation of such exchange fluxes as well as an opportunity to gain insight into the metabolic behavior of individual cell types. Here, we estimated the availability of nutrients and oxygen within the tumor microenvironment using concentration measurements from blood together with a metabolite diffusion model. In addition, we developed an approach to efficiently apply enzyme usage constraints in a comprehensive metabolic model of human cells. The combined modeling reproduced severe hypoxic conditions and the Warburg effect, and we found that limitations in enzymatic capacity contribute to cancer cells' preferential use of glutamine as a substrate to the citric acid cycle. Furthermore, we investigated the common belief that some stromal cells are exploited by cancer cells to produce metabolites useful for the cancer cells. We identified a total of 233 potential metabolites that could support collaboration between cancer cells and cancer associated fibroblasts, but when limiting to metabolites previously identified to participate in such collaboration, no growth advantage was observed. Our work highlights the importance of enzymatic capacity limitations for cell behaviors and exemplifies the utility of enzyme constrained models for accurate prediction of metabolism in cells and tumor microenvironments. 
bioRxiv preprint doi: https://doi.org/10.1101/2022.02.08.479584; this version posted February 10, 2022. The copyright holder for this preprint (which was not certified by peer review) is the author/funder, who has granted bioRxiv a license to display the preprint in perpetuity. It is made available under aCC-BY 4.0 International license.

\section{Introduction}

The tumor microenvironment (TME) consists of many different cell types that share a common influx of metabolites from the blood. The availability of nutrients can vary substantially within a tumor, where the proximity to functional capillaries is crucial for access to metabolites. Tumor cells are generally thought to strive for proliferation, but the metabolic behavior that is optimal for maximizing growth will depend on the availability of metabolites. It is therefore not possible to describe a general optimal behavior for tumor cells for maximizing growth.

The TME is characterized by leaky blood vessels, which lead to high internal tumor pressure and incapacitate the microcirculation and flux of fluid from the blood, through the tumor, and into the lymph vessels (1-3). The main mechanism for transport of metabolites and oxygen from the blood to the cells is therefore diffusion (4). Furthermore, the blood vessel density is unevenly distributed, leading to both a lack of nutrients and hypoxia in some areas. Hypoxic and even necrotic regions tend to be more common in the center of the tumor, while the regions close to the edge have better access to capillaries (5).

The metabolism in tumors is different from that of normal cells. Cancer cells often produce more lactate, due to hypoxia or within oxygenated regions to maximize growth, which is known as the Warburg effect (6). The latter behavior is not unique to cancer but is shared with other cells that strive to grow rapidly, for example dividing T cells (7). In addition, many cancers exhibit so-called glutamine addiction, where the tricarboxylic acid (TCA) cycle is preferentially fed with metabolites originating from glutamine instead of pyruvate from glycolysis (8).

Collaboration scenarios between different "healthy" cell types and tumor cells, where cells such as fibroblasts and macrophages are thought to be exploited by the cancer cells, has been a topic of great interest for the last decade (9-12). Specifically, these cells are thought to regulate the tumor microenvironment through signaling as well as provide nutrients such as lactate and pyruvate to the tumor cells to enhance their growth. Partial evidence of the latter has been presented, where cancer-associated fibroblasts have been observed to secrete metabolites that were taken up by cancer cells (11), but there is no solid evidence that such collaboration is directly beneficial for growth.

Genome-scale modeling (13) of human metabolism involves performing in silico analyses of a reaction network under steady-state conditions and has been used to investigate metabolism in muscles (14), tumor cell lines (15), and Alzheimer's disease (16), for example. A common method to estimate metabolic fluxes through the network is flux balance analysis (FBA), where the net production or depletion of all internal metabolites is assumed to be zero. A recent approach is the GECKO framework (17), which enables the integration of enzyme kinetic data with genome-scale metabolic models to simulate more physiologically meaningful flux distributions even when metabolite exchange rate data is limited.

Cell lines are often used as cancer models, and can be examined in a controlled environment to for example measure specific growth rate and metabolite uptake fluxes (18), which in turn can be used to constrain metabolic models (15). However, it is challenging to create a realistic in vitro environment with limited nutrient and oxygen supply where the cells are assumed to behave in a similar way as in vivo. On the other hand, it is challenging to measure the uptake and secretion of metabolites from cells in vivo, especially for multiple metabolites simultaneously, although some successful measurements of for example lactate uptake have been made using substrates labeled 
bioRxiv preprint doi: https://doi org/10.1101/2022 $02.08 .479584 \cdot$ this version posted February 10,2022 . The copyright holder for this preprint (which was not certified by peer review) is the author/funder, who has granted bioRxiv a license to display the preprint in perpetuity. It is made available under aCC-BY 4.0 International license.

with isotopes (19). Other approaches to estimate the metabolite uptake constraints are therefore needed.

An alternative to measuring metabolite uptake rates of cells at different tumor regions and using those measurements to evaluate collaboration scenarios is to investigate metabolic collaboration of different cell types using genome-scale modeling. Here we developed a diffusion model for constraining metabolite uptake rates in tumors and applied enzyme constraints to a human genomescale model to determine which metabolites are limiting for growth and the effect that collaboration scenarios can have on tumor growth. Our metabolic models show that glucose and oxygen are the most limiting substances for growth. Furthermore, they predict the glutamine addiction phenomenon, where a higher ATP yield is possible when the TCA cycle is fueled with glutamine compared to pyruvate due to less enzyme usage per ATP produced. In addition, we observe that the previously described direct metabolic collaboration between cancer-associated fibroblasts (CAFs) and cancer cells is negligible, and likely has a very small effect on tumor growth. 


\section{Results and discussion}

\section{Simulation of tumor cell growth}

We used the genome-scale metabolic model Human1 (20) enhanced with enzyme constraints to model the metabolism of cancer cells in the tumor microenvironment. The model was manually curated (Methods) and a non-growth associated maintenance (NGAM) requirement was added as an ATP cost of $1.833 \mathrm{mmol} \mathrm{gDW}^{-1} \mathrm{~h}^{-1}$ derived from literature $(21,22)$. We developed a lightweight version of the GECKO toolbox $(17,23)$, called GECKO Light, which similarly to GECKO constrains the total metabolic enzyme usage based on $k_{c a t}$ values from the BRENDA database (24). The main improvement in GECKO Light is a substantially decreased execution time ( 2 minutes on a standard laptop computer) and a smaller generated model size (only 1 reaction and 1 metabolite is added to the model). GECKO Light is described in more detail in Note S1.

It is challenging to measure metabolite fluxes in the tumor microenvironment. Given that diffusion is deemed to be the dominant mechanism for influx of metabolites into tumors (25), we developed a diffusion model that uses the metabolite concentrations in blood and their diffusion coefficients to estimate the metabolite uptake constraints (Fig. 1A). Instead of estimating absolute uptake constraints, which are expected to vary across cells depending on many factors such as distance to capillaries, we estimated relative uptake constraints according to

$$
U_{i}=a D_{i} c_{b, i}
$$

where $U_{i}$ is the estimated upper bound for the uptake flux of metabolite $i, a$ is a proportionality constant that is inversely related to the distance to the closest capillaries, $D_{i}$ is the diffusion coefficient for metabolite $i$, and $c_{b, i}$ is the concentration of metabolite $i$ in the blood. While the value of $a$ varies across cells and is difficult to estimate for a given cell, its value will be the same for all metabolites within the same cell, which makes it possible to investigate the metabolism at different pseudodistances from blood vessels. A detailed derivation of the diffusion model is available in Note S2. 
A
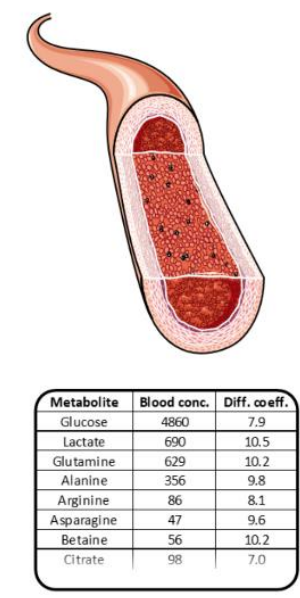

B

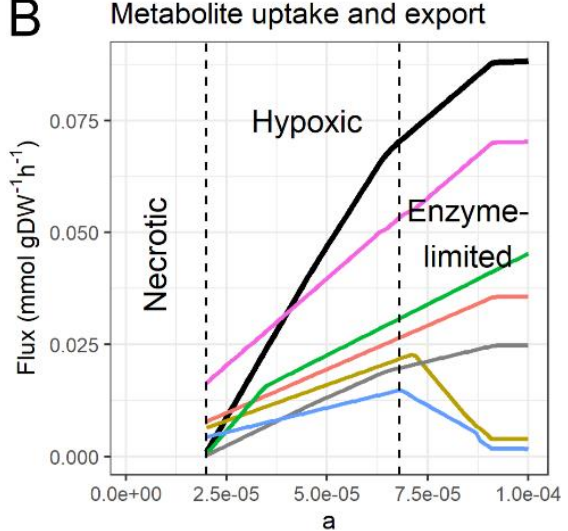

Cancer cell
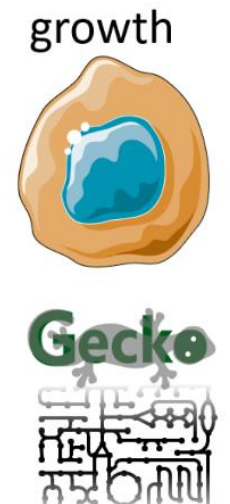

Human1

Fig. 1: Modeling cancer cell growth in the tumor microenvironment. A. Modeling setup. The metabolite uptake bounds are estimated from a diffusion model based on metabolite concentrations in blood and their diffusion coefficients. In addition, enzyme usage constraints are added to the model using GECKO Light. B. Simulated specific growth rate (biomass production) and metabolite exchange rates for different values of a using the diffusion model. Some fluxes are multiplied with a factor to make it possible to view all of them in the same figure: glucose upt.: 0.01, glutamine upt.: 0.05, Lipid pool upt.: 0.2, cholesterol upt.: 10 , oxygen upt.: 0.1, and lactate exp.: 0.01. C. Internal fluxes in the same simulations as $B$. The glycolytic flux is multiplied by 0.01 and the fluxes through the complexes are multiplied by 0.1 .

We retrieved blood plasma measurements from several sources to form a collection of 69 metabolites with associated concentration values (26-29). Lipids were grouped into sterols (represented by cholesterol) and other lipids (fatty acyls, glycerolipids, glycerophospholipids, and sphingolipids, represented as a mix of fatty acids). For oxygen we used the concentration of free oxygen, which can diffuse, excluding roughly $98 \%$ of the total concentration in blood that is bound to hemoglobin. A more detailed description of the estimation of metabolite concentrations in blood is available (Note S3; Table S1, S2, and S3; Fig. S1).

We collected 18 metabolite diffusion coefficients from literature (30-32), and estimated the remaining coefficients using a linear model based on molecular mass (33). Lipids are not soluble in water and are therefore transported together with albumin or a lipoprotein, or potentially as droplets. These are large particles that do not diffuse well, and we modeled the diffusion of these particles by using the diffusion coefficient of albumin for all lipids. The estimated diffusion constants are described in more detail in the supplementary information (Fig. S2, Note S4, Table S3). 
bioRxiv preprint doi: https://doi.org/10.1101/2022.02.08.479584; this version posted February 10, 2022. The copyright holder for this preprint (which was not certified by peer review) is the author/funder, who has granted bioRxiv a license to display the preprint in perpetuity. It is made available under aCC-BY 4.0 International license.

We first simulated the tumor cell growth for different values of the proportionality constant $a$ using FBA (Fig. 1B). For small values of $a$ (greater distances from capillaries), the model cannot produce enough ATP to uphold cell maintenance requirements, resulting in necrosis. For higher values of $a$, we see a hypoxic region where the cells can survive and grow but are limited in growth by availability of nutrients and oxygen, followed by a region where the enzyme constraints become the major limiting factor for growth, representing the Warburg effect. There is a general shortage of oxygen for small values of $a$ - the limited amount that is available is mainly used for oxidative phosphorylation. These large and slow enzyme complexes of the electron transport chain (ETC) provide much ATP per substrate and regenerate some of the NAD+ needed for glycolysis, however, at a large enzymatic cost. To replenish the remaining NAD+, pyruvate is converted to lactate and exported out of the cells. With greater availability of nutrients, a higher specific growth rate can be reached by decreasing oxidative phosphorylation and instead allocating more of the total enzymatic capacity to glycolysis. The simulation predicts an early bypass of complex I, while the remaining ETC complexes remain active at a wider $a$ range (Fig. 1C), which is consistent with a previous study where complex I bypass was described to increase ATP yield at the cost of a lower substrate efficiency (14). Our model compensates the lost conversion of NADH to NAD+ from complex I bypass by using other pathways with a lower enzymatic cost, typically involving amino acids or fatty acids. The model exhibits an extreme behavior where oxidative phosphorylation is completely shut down for large values of $a$. In practice, such a behavior is generally not observed. $80 \%$ of the ATP has for example been reported to be generated by oxidative phosphorylation in some highly proliferative cells (34), but regardless of this limitation the model can still serve as a means to understand observed metabolic behaviors. For very large values of $a$, the growth can be increased further by using rare substrates. The preferred substrate by the model is thymidine, which feeds glycolysis and gradually replaces glucose due to a low enzymatic cost. It is difficult to know if these behaviors mirror those in vivo, but thymidine may contribute to growth; it has previously been reported that thymidine is indeed helpful, at least in glucose-deprived conditions (35).

To evaluate which metabolites are limiting for growth, we performed flux variability analysis (FVA), where for different values of $a$ we fixed the specific growth rate at its maximum value and minimized the uptake of each metabolite individually (Fig. S3). Oxygen, glucose, amino acids (only glutamine shown), and lipids were generally growth limiting for low values of $a$, where glucose was limiting for the widest $a$ range. Neither lactate nor albumin was limiting for growth, since neither of them can give a positive ATP contribution without using oxygen. We also investigated the effect on growth when reducing the uptake of individual metabolites, which clearly showed that glucose and oxygen were by far the two most important metabolites for growth, followed by a smaller effect from glutamine, while the other limiting metabolites had a less pronounced effect (Fig. S4). As expected, free access to oxygen yielded a clear increase in growth for low values of $a$, emphasizing the importance of hypoxia (Fig. S5). To investigate which cellular processes are limiting for growth we repeated our simulations with different parts of the biomass reaction removed, which showed that ATP production was the main limiting factor (Fig. S6). To assess the sensitivity of our results, we repeated our analyses with the growth-associated ATP cost and NGAM reduced to $50 \%$ and $25 \%$ of their original values, which confirmed that glucose and oxygen were still the most important contributors to growth (Fig. S7). 


\section{Amino acid metabolism}

Amino acid metabolism in tumors is a topic that has received much attention recently, and we decided to investigate this process in more detail. The model predicted large uptake fluxes of glutamine, glycine, serine, and threonine, while proline and aspartate were exported (Fig. 2A). In addition, arginine, asparagine, cysteine, glutamate, histidine, and valine exhibited varying uptake behaviors for different values of $a$, while remaining amino acids were taken up at a rate proportional to the specific growth rate and were used primarily for protein synthesis (Fig. 2B, S8). The model did not predict glutamate secretion, which is observed in some cancer cell lines $(15,36)$. While glutamate export has previously been linked to nucleotide synthesis (15), our model does not predict any advantage of such a behavior in the TME. Glutamate is also a central signaling molecule, and glutamate secretion in glioblastoma has been linked to signaling effects, leading to a growth advantage $(37,38)$.

A

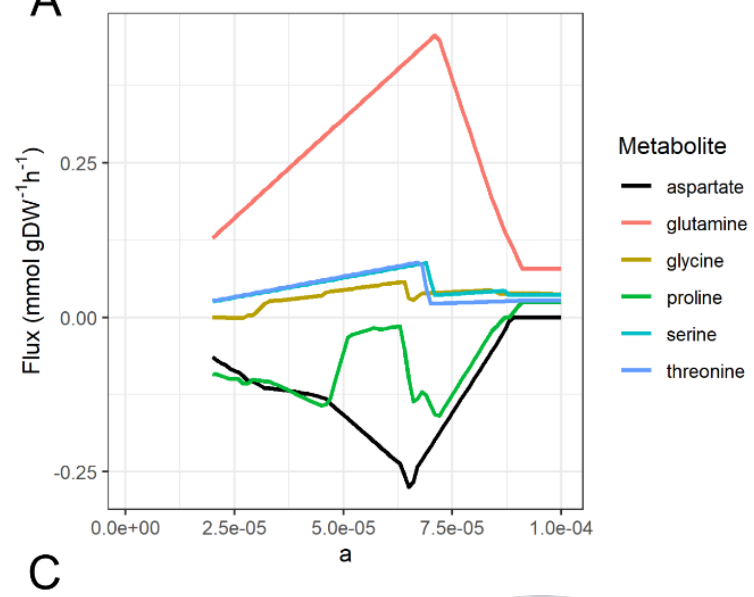

B

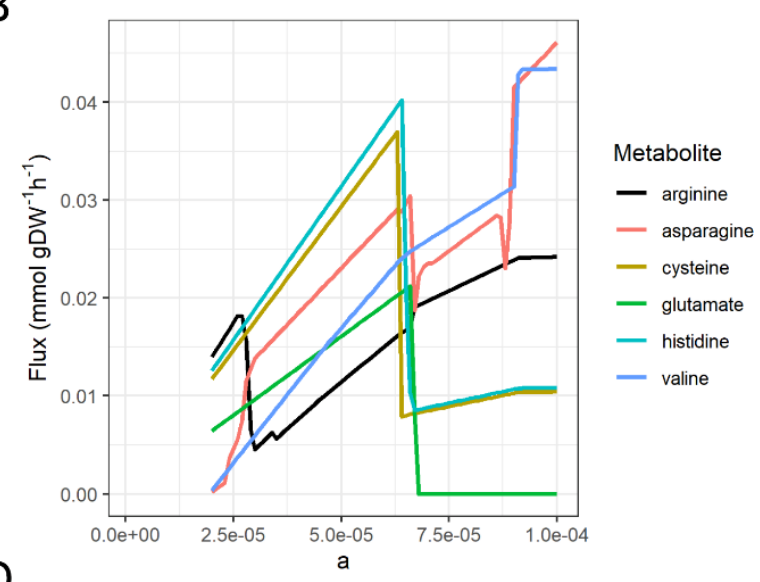

Extracellular space
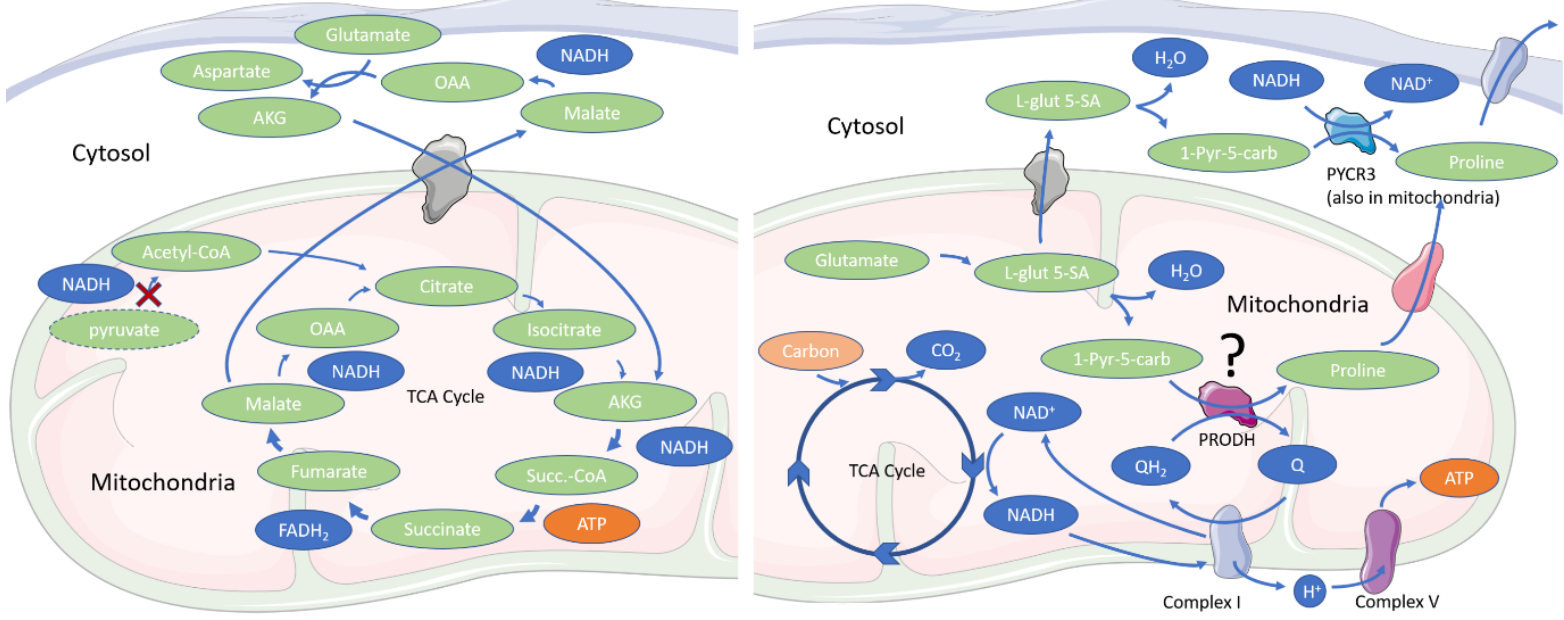

Fig. 2: Predicted amino acid metabolism in simulation of cancer cell growth. $A$ and $B$ show amino acid fluxes from the simulation used in Fig. 1B. A. Amino acids with high predicted fluxes. Positive fluxes correspond to cellular uptake and negative to export. B. Amino acids with low uptake rates for which the uptake behavior varies with a (cellular uptake only). C. Predicted "glutamine addiction" mechanism. When OXPHOS is limited by its high enzyme usage, the TCA cycle flux is limited because there is no way for the cell to oxidize the produced NADH/FADH. Any processes that can either limit the production of NADH/FADH $H_{2}$ while running the TCA cycle or increase oxidation of NADH/FADH 2 will thus lead to a possibility to increase the flux through the TCA cycle, and thereby increase the ATP production. Feeding the TCA cycle from glutamate instead of pyruvate shortcuts the TCA cycle, 
bioRxiv preprint doi: https://doi.org/10.1101/2022.02.08.479584; this version posted February 10, 2022. The copyright holder for this preprint (which was not certified by peer review) is the author/funder, who has granted bioRxiv a license to display the preprint in perpetuity. It is made available under aCC-BY 4.0 International license.

reducing two less $N A D+$ molecules to $N A D H$, while also preserving pyruvate that can be converted into lactate to oxidize another NADH molecule. The thickness of the arrows indicates the amount of flux that passes through the reactions, where thick arrows represent high flux. D. Proline metabolism. Generation of proline can help to increase flux through the TCA cycle and thereby increase ATP production. The model predicts two mechanisms for this purpose: 1) Oxidation of NADH through any of the PYCR enzymes. 2) By running PRODH in reverse. This would have the effect of increased flux through complex I, since 1-pyrroline-5-carboxylate would replace oxygen as the electron acceptor in the electron transport chain, and could therefore in theory increase ATP production by consuming excess NADH and increasing flux through complex $V$.

The genome-scale metabolic model can be used to in detail study the most optimal amino acid metabolism in different conditions, where the $\mathrm{NADH} / \mathrm{FADH}_{2}$ oxidation ratio in the ETC plays an important role. For fast growing cells limited by enzymatic capacity, the ratio should be as low as possible to maximize ATP production (complex I bypass), while the ratio should be as low as possible in oxygen-deprived conditions (Note S5). Cells can utilize amino acids in different ways to manipulate this ratio.

"Glutamine addiction" is a well-known trait of many cancers (8,39-41), where glutamine, the most highly abundant amino acid in blood, is used instead of glucose-derived pyruvate to feed the TCA cycle. Indeed, the model predicts such behavior. Glutamine is converted to glutamate and enters the TCA cycle, producing 3 less NADH per cycle than if pyruvate is used (Fig. 2C). A consequence of this behavior is the export of aspartate, which was not observed in a cell culture experiment of the $\mathrm{NCl}$ 60 cell lines (18). However, aspartate can be converted to lactate (via fumarate, malate, and pyruvate) without requiring ATP or altering the redox balance, which may explain why aspartate export is not observed. This process couples the oxidation of NADH to NAD+ with the reduction of $\mathrm{NADP}^{+}$to NADPH, which may impact other processes. In addition, export of dihydroorotate has also been reported in hypoxic conditions, posing as an alternative pathway for disposing of aspartate (40). Interestingly, it has been reported that different cell lines have different strategies for aspartate supply; some do not express aspartate transporters and rely on ETC activity for aspartate production, which is consistent with our modeling results, while others rely on import (42).

The model also predicts proline secretion, which is observed for some NCl-60 (18) cell lines as well as in HEK293 cells (15). The model predicts two different mechanisms by which proline production from glutamate can help to increase ATP production: NADH oxidation through PYCR3 (or related enzymes) or by running PRODH in reverse, enabling the use of complex I without oxygen (Fig. 2D, Fig. S9). The latter has to our knowledge not been reported, and it is unclear if such a reaction is thermodynamically favorable, but in theory it could yield additional ATP in hypoxic nutrient-deprived conditions and thus further motivate glutamine addiction in cancers. It has been shown that complex II, which catalyzes a similar reaction, can be run in reverse in rats (43), making the reversed PRODH reaction an intriguing hypothesis for motivating proline export.

To investigate the behavior of each amino acid in more detail, we simulated access to a fixed influx of a single metabolite and optimized for maximum ATP production, comparing the use of each amino acid as single carbon source to that of using lactate (Table 1). We first examined a condition characterized by hypoxia and a reasonably small availability of nutrients, where the ATP production is limited by oxygen availability and enzyme limitations is expected to have a negligible effect. With the reverse PRODH reaction active, many amino acids yield a higher amount of ATP than lactate when used as carbon source, but the effect is lost for most amino acids when the reverse PRODH reaction is blocked. We next explored the utilization of amino acids under enzymatic constraints. Under enzyme-limited conditions, the overall picture changes - glutamine and glutamate now 
bioRxiv preprint doi: https://doi.org/10.1101/2022.02.08.479584; this version posted February 10, 2022. The copyright holder for this preprint (which was not certified by peer review) is the author/funder, who has granted bioRxiv a license to display the preprint in perpetuity. It is made available under aCC-BY 4.0 International license.

become the carbon sources giving the highest ATP yield, consistent with the strategy depicted in Fig. $2 \mathrm{C}$ and the glutamine addiction results reported previously (8). While such an effect was not observed for hypoxic conditions with low enzyme usage, complex I is bypassed and the TCA cycle flux is under enzyme-limited conditions several times higher for glutamine, yielding a higher total ATP production despite having lower complex $V$ activity (Fig. S10). Furthermore, the PYCR3 reaction (or similar reactions) is used to produce proline, oxidizing 2 equivalents of NADH. A previous study showed that glutamine is used to feed the TCA cycle both in hypoxic and normoxic conditions, which is consistent with our results since the cells in both these cases were cultured in nutrient-rich medium, implying that enzymatic capacity is likely limiting for growth, regardless of hypoxia or not (34). In addition, enzyme usage is not only limited, but comes at a maintenance cost that we only model as a fixed cost independent of actual usage. So, although the cell may not be hindered by its enzymatic capacity, there may still be a reason to minimize the enzyme usage.

Table 1: ATP production from amino acids compared to lactate in different settings. The table shows the maximum ATP production $\left(g D W^{-1} h^{-1}\right)$ given a maximal uptake of $5 \mathrm{mmol}^{*} g D W^{-1} h^{-1}$ of a single substrate and varying oxygen availability. " $\mathrm{O}_{2}$-limited": The oxygen uptake is constrained to 5 mmol ${ }^{*} g D W^{-1} h^{-1}$, which is not enough to fully oxidize any of the substates. "O $\mathrm{O}_{2}$-limited, no PRODH": In addition to "O-limited" the reverse PRODH reaction is also blocked. "No $\mathrm{O}_{2}$, no PRODH": The $\mathrm{O}_{2}$ uptake is zero and the reverse PRODH reaction is blocked. "Enzyme Lim.": The total available enzyme pool is constrained to a low value $(0.001 \mathrm{~g} / \mathrm{gDW})$. In practice, this also means that the reverse PRODH reaction will not be used. Green background corresponds to a higher ATP production compared to lactate, white to identical, and red to a lower flux. While comparison to using pyruvate as fuel may at first seem more relevant since pyruvate is the alternative fuel for the TCA cycle coming from glycolysis, we need to keep in mind that if not used, the pyruvate will be exported as lactate, making comparison to lactate fairer from a redox perspective.

\begin{tabular}{|l|l|l|l|l|}
\hline Substrate & Low $\mathbf{O}_{2}$ & $\begin{array}{l}\text { Low } \mathbf{O}_{2}, \text { no } \\
\text { PRODH }\end{array}$ & $\begin{array}{l}\text { No O }, \text { no } \\
\text { PRODH }\end{array}$ & Enzyme lim. \\
\hline lactate & 5 & 5 & 0 & 0.0938 \\
\hline aspartate & 6.5 & 5 & 0 & 0.0937 \\
\hline glutamine & 10 & 5 & 0 & 0.1042 \\
\hline glycine & 5.7 & 5.7 & 0 & 0.0929 \\
\hline proline & 4.7 & 4.7 & 0 & 0.0943 \\
\hline serine & 9 & 9 & 3.33 & 0.0945 \\
\hline threonine & 9 & 9 & 3.33 & 0.0931 \\
\hline alanine & 5 & 5 & 0 & 0.0932 \\
\hline arginine & 12.3 & 5 & 0 & 0.0942 \\
\hline asparagine & 6.5 & 5 & 0 & 0.0940 \\
\hline cysteine & 5 & 5 & 0 & 0.0927 \\
\hline glutamate & 10 & 5 & 0 & 0.1020 \\
\hline histidine & 11.1 & 5 & 0 & 0.0923 \\
\hline isoleucine & 5 & 5 & 0 & 0.0921 \\
\hline leucine & 5 & 5 & 0 & 0.0917 \\
\hline lysine & 4.8 & 4.8 & 0 & 0.0918 \\
\hline methionine & 5 & 5 & 0 & 0.0830 \\
\hline phenylalanine & 5 & 5 & 0 & 0.0900 \\
\hline tryptophan & 3.8 & 3.8 & 0 & 0.0877 \\
\hline tyrosine & 5 & 5 & 0 & 0.0915 \\
\hline valine & 5 & 5 & 0 & 0.0917 \\
\hline
\end{tabular}




\section{Simulation of cell type collaborations in the TME}

A topic that has drawn some attention the last decade is whether non-cancerous cells in the TME assist the cancer cells metabolically by providing them with resources that are advantageous for growth. It has for example been proposed that cancer-associated fibroblasts (CAFs) can provide cancer cells with metabolites such as lactate and pyruvate $(9,44)$, and it could also be beneficial if tumor-associated macrophages (TAMs) could consume dead cells and cellular debris and produce nutrients for the cancer cells. We sought to investigate these collaboration scenarios in more detail using our diffusion modeling approach. We again constrained metabolite uptake from blood but built a more complex metabolic model consisting of three cell types: cancer cells, fibroblasts, and other cells, where the latter represent cells that are not expected to provide resources to the cancer cells, for example immune cells (Fig. 3A). The exchange of metabolites between the cell types was controlled by providing separate compartments for the interstitium around the fibroblasts and other cells (Fig. 3B).

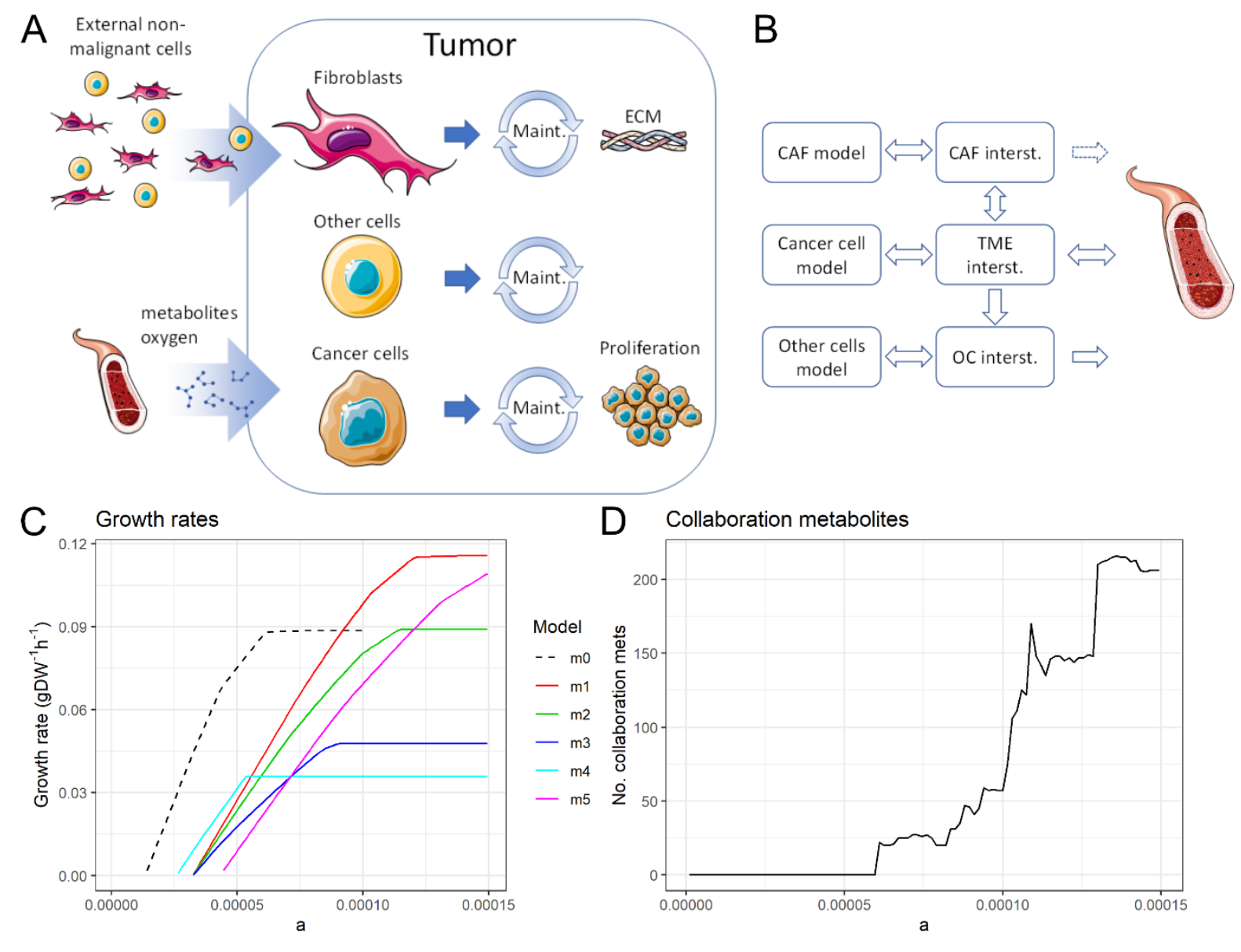

Fig. 3: Collaboration between cell types in the TME. A. Modeling setup of the tumor microenvironment. The model contains three cell types: Fibroblasts (CAFs), cancer cells, and other cells (e.g. different types of immune cells). Non-malignant cells are imported to the tumor, resulting in a total biomass reaction consisting of cancer cell growth and extracellular matrix construction. All cell types have the same metabolic network (the curated full Human1 model) with the same NGAM value as used previously, but the fibroblasts were extended with reactions for building the extracellular matrix. B. Compartment setup to enable limitation of cell type collaboration to certain scenarios. The fibroblasts (CAF) and other cells (OC) have their own model compartments for the tumor interstitium. While metabolites can (depending on the simulation) be transported from the 
bioRxiv preprint doi: https://doi.org/10.1101/2022.02.08.479584; this version posted February 10,2022 . The copyright holder for this preprint (which was not certified by peer review) is the author/funder, who has granted bioRxiv a license to display the preprint in perpetuity. It is made available under aCC-BY 4.0 International license.

CAF interstitium to the cancer cell interstitium, such transport is not possible from the $O C$ insterstitium. C. Effect of collaboration on the specific growth rate of the tumor. D. Number of collaboration metabolites between fibroblasts and cancer cells as a function of $a$, measured for the m2 model.

The ECM consists mainly of collagens and glycosaminoglycans (GAGs) and is produced by the fibroblasts. Both the composition of the ECM and the fraction of the total tumor dry weight that the ECM constitutes vary largely across tumors. We assumed an ECM composition of $80 \%$ collagen (represented by collagen I) and $20 \%$ GAGs (represented by heparan sulfate) to reduce the number of flexible parameters. We varied the total ECM fraction of the tumor dry weight and the fraction of each cell type, since these parameters vary substantially between individual tumors. The different modeling configurations are listed in Table 2.

Table 2. Different model configurations used in the simulations. The mo model contains only tumor cells and is identical to the model used in Fig. 1 and 2. ECM fraction represents the weight fraction of the total objective being maximized that the ECM constitutes.

\begin{tabular}{|l|l|l|l|l|}
\hline Model & $\begin{array}{l}\text { Cancer } \\
\text { cell frac. }\end{array}$ & $\begin{array}{l}\text { Fibr. } \\
\text { cell frac. }\end{array}$ & $\begin{array}{l}\text { Other } \\
\text { cells frac. }\end{array}$ & $\begin{array}{l}\text { ECM } \\
\text { frac. }\end{array}$ \\
\hline $\mathrm{m} 0$ & 1 & 0 & 0 & 0 \\
\hline $\mathrm{m} 1$ & 0.6 & 0.2 & 0.2 & 0.01 \\
\hline $\mathrm{m} 2$ & 0.6 & 0.2 & 0.2 & 0.25 \\
\hline $\mathrm{m} 3$ & 0.6 & 0.2 & 0.2 & 0.5 \\
\hline $\mathrm{m} 4$ & 0.75 & 0.05 & 0.2 & 0.25 \\
\hline $\mathrm{m} 5$ & 0.45 & 0.35 & 0.2 & 0.25 \\
\hline $\mathrm{m} 6$ & 0.9699 & 0.0001 & 0.03 & 0.00001 \\
\hline
\end{tabular}

It directly follows from the first law of thermodynamics that CAFs cannot increase the total energy available in the TME unless they actively import or utilize material from outside the TME, which is a case we don't investigate here. In cases where the growth is limited by nutrient availability only, there is nothing the CAFs can do to help the cancer cells metabolically, given that the cancer cells behave optimally and thereby express the enzymes needed to utilize the available nutrients. However, as nutrient availability increases and the growth becomes limited by enzymatic capacity, it is possible for the CAFs to increase growth by providing enzymatic capacity for producing metabolites that are more optimal for cancer cell growth. In our simulations, we thus focus on the scenario where CAFs lend the cancer cells their enzymatic capacity.

We first simulated the specific growth rates of the models with different parameter values for ECM and cell type fractions (m1-m5) and compared them to that of the $\mathrm{mo}$ model (Fig. 3C). A high fraction of fibroblasts penalized growth at low values of $a$, where growth is mainly limited by availability of nutrients, since the fibroblasts consumed nutrients to support non-growth associated maintenance. On the other hand, the fibroblasts helped to increase the specific growth rate at high values of $a$ by lending enzymatic capacity to the cancer cells. We also observed that the cost of building the ECM was not negligible in our simulations. However, the addition of ECM to the model objective function did not substantially alter which metabolites were limiting for growth relative to the $\mathrm{mo}$ model, despite a high protein content (Fig. S11A). 
bioRxiv preprint doi: https://doi.org/10.1101/2022.02.08.479584; this version posted February 10, 2022. The copyright holder for this preprint (which was not certified by peer review) is the author/funder, who has granted bioRxiv a license to display the preprint in perpetuity. It is made available under aCC-BY 4.0 International license.

To investigate the potential collaboration between fibroblasts and cancer cells in more detail, we implemented an iterative algorithm to identify potential collaboration metabolites (Methods), which were defined as metabolites exported from the fibroblasts and consumed by cancer cells when optimizing the model for maximum tumor growth. We identified the collaboration metabolites for each value of $a$ for the $\mathrm{m} 2$ model, which is the model with middle values of the parameters ECM fraction and fibroblast cell fraction (Table S4) and summed the number of collaboration metabolites per value of $a$ (Fig. 3D). As expected, we did not find any collaboration metabolites for low values of $a$ but identified an increasing number for higher values of $a$, where the enzymatic capacity becomes limiting for growth. We identified in total 233 potential collaboration metabolites across the range of explored $a$ values. However, many of these collaboration metabolites, such as ATP, are not physiologically meaningful and have not been reported as being exported from fibroblasts. When limiting the collaboration metabolites to those reported in literature (lactate, pyruvate, free fatty acids, glutamine, ketone bodies, and alanine $(44,45))$, and comparing with the model where collaboration is blocked, the growth difference is negligible (Fig. S11B). Interestingly, co-injection of tumor cells with fibroblasts in mice leads to an increased specific growth rate (46). We reason that this effect is likely caused by signaling effects or because the fibroblasts complement deficiencies in the metabolic functionality of the tumor cells.

Although the "other cells" cannot provide the cancer cells with resources in the simulation, they can still minimize their negative impact on growth, which we have termed passive collaboration. We simulated this behavior by maximizing tumor growth using the $\mathrm{m} 6$ model, resulting in ATP generation based on enzyme-demanding processing such as oxidative phosphorylation in the other cells (Fig. S11C). The question is whether the other cells, representing for example immune cells, are helpful for cancer growth, or if the relationship is more competitive. TAMs have however been reported to switch to oxidative phosphorylation when exposed to lactate, which is a sign of such passive collaboration (47).

Tumor-associated macrophages are reported to have many metabolic roles in the TME, including both passive and active collaboration $(47,48)$, which would give them the same role as other cells or fibroblasts in our simulation. Macrophages however also have an additional function where they can scavenge dead cells and convert them into metabolites useful to other cells. To investigate to what extent this function can support tumor growth, we used the $m 0$ model and assumed that $10 \%$ of the tumor cells produced from growth die. We assumed that the maximum amount of extra nutrients provided is thus the metabolites that constitute $10 \%$ of the produced biomass (Methods), excluding the ATP cost consumed during growth (Table S5). There is a clear growth advantage, which is larger for small $a$ values, but the overall effect is relatively small even though no maintenance or metabolite conversion cost is included for the macrophages (Fig. S11D). The reason for the limited usefulness of such substrates is mainly that in nutrient-deprived conditions all oxygen is already being consumed, and oxygen is required to generate ATP from most scavenged resources. A similar theory to that of scavenging dead cells by macrophages concerns catabolism of organelles and apoptosis in CAFs to provide additional nutrients (9), where CAFs could then for example be recruited to the tumor. Such a case could provide a small growth advantage similar to the macrophage case but also suffers from the same problem of oxygen limitation and is likely of limited importance.

It has been reported that oxygenated cancer cells (from well oxygenated regions of the tumor, representing a large value of $a$ ) collaborate with hypoxic cancer cells (from hypoxic regions, representing a lower $a$ value) by consuming lactate $(49,50)$. Less glucose will then be spent in the well oxygenated regions and can diffuse to the hypoxic areas. Indeed, Sonveaux et al (49) presented 
bioRxiv preprint doi: https://doi.org/10.1101/2022.02.08.479584; this version posted February 10, 2022. The copyright holder for this preprint (which was not certified by peer review) is the author/funder, who has granted bioRxiv a license to display the preprint in perpetuity. It is made available under aCC-BY 4.0 International license.

experimental evidence that the necrotic regions of tumors increased in size in a mouse model when blocking lactate uptake. A problem with this theory is that a corresponding increase in oxygen uptake is expected in the well oxygenated regions, since more oxygen is required to produce the same amount of ATP from lactate as compared to glucose, and less oxygen therefore will diffuse to the hypoxic regions, potentially counteracting the beneficial effect. An alternative or complementary theory could be that the increase in necrotic regions is related to the extracellular lactate concentration, which is governed by a balance between lactate production in the cells in those regions and lactate diffusing away from the tumor core. The diffusion rate will be higher if surrounding tissue (and the rest of the body) consume lactate as this will increase the lactate concentration gradient, and blocking of lactate uptake in all cells could therefore lead to a lower diffusion rate, and a lower $\mathrm{pH}$. The internal $\mathrm{pH}$ in cells need to stay above a certain level for cell survival $(41,50-52)$, and it has been proposed that lowering the external $\mathrm{pH}$ makes active regulation of internal pH increasingly demanding, leading to a larger ATP need for the cells $(51,53)$. Under this assumption, a decrease in lactate diffusion may lead to an upper limitation of lactate production in the cells. We investigated the impact of such a scenario on growth by constraining the maximum lactate output to half of the glucose uptake bound, which showed a large negative impact on growth and an increase of the necrotic region (Fig. S11E). In addition, it has been shown that mammalian cells that are not under stress generally tend to take up lactate whenever available (19), for example to regulate the $\mathrm{pH}$ of blood and tissue, and cancer cells may have simply retained this behavior from healthy cells. The observed lactate uptake in well oxygenated regions of the tumor may therefore not necessarily be beneficial for growth in the tumor core.

\section{Model limitations}

Our modeling approach is based on many assumptions that when violated could affect the results the uptake constraints of oxygen and lipids are particularly uncertain. Oxygen levels are not expected to substantially affect the modeling results as long as oxygen levels are low, which is a known characteristic of tumors. The model will in that case behave similarly in a qualitive way, although quantitative results, such as the width of the necrotic region or to what extent a certain metabolite is limiting, could be affected. Quantitative results concerning lipids should be interpreted with caution due to uncertainties in lipid diffusion rates. Another limitation of the model is the quality of the $k_{\text {cat }}$ values used for the enzyme constraints. Reliable measurements are simply missing for many enzymes, and our prediction strategy leaves a fair amount of uncertainty in the estimated values, although the central carbon metabolism are well represented in $\mathrm{k}_{\text {cat }}$ databases.

Regardless of the limitations, the model was able to reproduce known behaviors of amino acid metabolism using only constraints on metabolite uptake and enzyme usage, providing confidence in its usefulness for investigating why such behaviors exist in cancer cells. We have in this work produced two major results based on modeling: we provide a possible explanation to glutamine addiction in cancers, and we show that there is little benefit from metabolic collaboration in the TME. These results are primarily based on the model structure, which represents the current understanding of which chemical reactions are available in human cells, and $\mathrm{k}_{\text {cat }}$ values, and are not particularly sensitive to parameter values in the diffusion model. The glutamine addiction mechanism is also consistent with experimental measurements, while the lack of metabolic collaboration in the TME is difficult to measure. 
bioRxiv preprint doi: https://doi.org/10.1101/2022 02 08.479584 this version posted February 10, 2022. The copyright holder for this

\section{Conclusion}

In this work, we sought to identify the metabolic behavior most optimal for growth in tumors at different levels of hypoxia. For this purpose, we used an enzyme-constrained genome-scale metabolic model where the metabolite uptake bounds were constrained according to a diffusion model based on metabolite concentrations in blood. We found that limitations in enzymatic capacity can explain why glutamine addiction is beneficial in cancers and that glucose and oxygen are the most limiting metabolites for growth. Furthermore, we found that metabolic collaboration scenarios previously described in the literature, where export of metabolites such as lactate and ketone bodies from cancer-associated fibroblasts to cancer cells were thought to increase tumor growth, have a negligible such effect. 
bioRxiv preprint doi: https://doi.org/10.1101/2022.02.08.479584; this version posted February 10,2022 . The copyright holder for this

\section{Methods}

\section{Model preparation}

We used the Genome-scale metabolic model Human1 (version 1.10) with added enzyme constraints (using Gecko Light, see Note S1). The model was manually curated by blocking 25 reactions, since they led to unrealistic fluxes (Table S6). All reactions that could not carry flux given the metabolites available in blood and Ham's media were removed using a modified version of the function "haveFlux" in RAVEN Toolbox 2.0 (54), except for the macrophage simulation where all reactions were retained since new metabolites were added as input. Furthermore, a non-growth associated maintenance (NGAM) value of $1.833 \mathrm{mmol}^{*} \mathrm{gDW}^{-1} \mathrm{~h}^{-1}$ was collected from literature $(21,22)$ and added to the model as a lower bound on the reaction MAR03964, representing hydrolysis of ATP to ADP.

\section{Combined model}

The combined model contained three cell types: CAFs, cancer cells and other cells, where the latter refers to cells that do not collaborate with the cancer cells, for example some types of immune cells (Fig. 3A). All three cell types were based on the curated Human1 model, but the CAFs were extended with reactions for building the extracellular matrix. Each cell type had its own interstitium compartment, where cancer cells had the TME interstitium compartment, which receives all metabolite influx from blood (Fig. 3B). This setup enabled control of metabolite flux between cell types, where the CAFs and cancer cells could exchange metabolites but the flux of metabolites between other cells and cancer cells was unidirectional towards the other cells. The tumor biomass function, which was used as objective, contained tumor cell growth and construction of ECM, where the latter was built by the CAFs. CAFs and other cells were assumed to be recruited to the tumor, and the biomass reactions of these cells were therefore not included in the total tumor biomass function. The ECM was composed of collagen I and GAGs (represented by Heparan sulfate) (Table S2). The protein cost in the ECM biomass reaction also included an ATP cost for polymerizing amino acids into peptides. There was a small enzyme usage cost added for transportation of metabolites from the fibroblast interstitium compartment to the TME interstitium, with the purpose of avoiding unnecessary transportation of metabolites between cell types (which could add additional collaboration metabolites).

\section{Modeling amino acid metabolism}

We used a special modeling configuration to generate the results in Table 1. For all setups, we first blocked the input of all metabolites and removed the protein usage constraint. We then set the upper bound of the input exchange reactions of water, phosphate, oxygen, and $\mathrm{H}^{+}$to infinity. The objective function was then set to maximize the flux through the ATP hydrolysis reaction (MAR03964), and the NGAM ATP cost was removed. For each metabolite, we then set the upper bound of the input exchange reaction of that metabolite to $10 \mathrm{mmol}^{*} \mathrm{gDW}^{-1} \mathrm{~h}^{-1}$. The optimization was run in several settings: "Low $\mathrm{O}_{2}$ ": Here, the upper bound of oxygen was set to $1 \mathrm{mmol}^{*} \mathrm{gDW}^{-1} \mathrm{~h}^{-1}$. "Low $\mathrm{O}_{2}$, no PRODH": Same as "Low $\mathrm{O}_{2}$ " but the reverse PRODH reaction ("MAR03838") is also blocked. "No $\mathrm{O}_{2}$, no PRODH": Same as "Low $\mathrm{O}_{2}$, no PRODH", but the oxygen upper bound is set to zero. "Enzyme Lim.": The protein usage was constrained to $0.001 \mathrm{~g} / \mathrm{gDW}$.

\section{Flux Balance Analysis (FBA)}

Flux balance analysis was performed using RAVEN Toolbox 2.0 with Gurobi (v. 8.1.1) as solver. 


\section{Flux Variability Analysis (FVA) to determine growth-limiting metabolites}

To identify growth-limiting metabolites, we first optimized the model for growth (maximization of flux through the biomass reaction). The lower bound of the biomass reaction was then set to the maximum specific growth rate (subtracted by $10^{-4}$ to avoid numerical issues in the solver), followed by an optimization for each metabolite $i$ of interest, where the flux of the metabolite's import exchange reaction was minimized, resulting in the minimum uptake rate $u_{m, i}$ needed to sustain the maximum specific growth rate. The minimum required fraction of the metabolite, $f$, was then calculated as

$$
f=u_{m, i} / u_{d, i}
$$

where $u_{d, i}$ is the maximum uptake rate of the metabolite as defined by the diffusion model.

\section{Identification of collaboration metabolites}

Potential collaboration metabolites for each value of $a$ were identified using an iterative algorithm on the $\mathrm{m} 2$ model. The algorithm in each iteration finds the potential collaboration metabolites, defined as metabolites that are exported from the fibroblasts and imported into the cancer cells when optimizing the model for total tumor growth using FBA. These metabolites are added to a list of potential collaboration metabolites and are then blocked from further collaboration by zeroing the upper bound of the transport reaction from the fibroblast interstitium compartment ( $f \_s$ ) to the TME interstitium compartment (s). The procedure is then repeated to identify new potential collaboration metabolites to add to the list, until no more such metabolites are found. Metabolites with infinite availability are excluded. We don't investigate if potential collaboration metabolites can actually contribute to growth since such an effect may be complex and is not easily identified.

\section{Macrophage collaboration}

To estimate the increase in uptake bound for metabolites from macrophage collaboration, we first derived the metabolite composition of the cells from the reaction "biomass_human", ignoring ATP (since it is spent during growth) and some lowly abundant metabolites. A few metabolites that did not have exchange reactions were either changed to a similar compound or removed. We then for each value of $a$ first optimized for growth. The additional metabolite availability $u_{a d d, i, x}$ for metabolite $i$ at $a=x$ was then calculated as

$$
u_{\text {add }, i, x}=n_{i} * g_{x} * f_{\text {dead }}
$$

where $n_{i}$ is the molar composition of metabolite $i$ in the biomass reaction ( $\left.\mathrm{mmol} / \mathrm{gDW}\right), g_{x}$ is the specific growth rate at $a=x$, and $f_{\text {dead }}$ is the fraction of cells produced that die, assumed to be 0.1 in the simulations. The fatty acid pool was converted to the metabolites "cholesterol" and "NEFA blood pool in". The metabolites and their concentrations are available in Table S5.

\section{Software}

The data was analyzed using MATLAB R2019b and R version 3.6.1. MATLAB was used for all analyses and the figures were generated in R. To ensure the quality of our analyses, we verified and validated the code using a combination of test cases, reasoning around expected outcome of a function, and code review. The details of this activity are available in the verification matrix available with the code. 


\section{Declarations}

\section{Availability of data and materials.}

The model Human1 is available in GitHub (https://github.com/SysBioChalmers/Human-GEM).

$\mathrm{k}_{\text {cat }}$ values are indirectly available in the Gecko Light repository in GitHub

(https://github.com/SysBioChalmers/GeckoLight). Metabolite concentrations and diffusion

coefficients are available in Table S3. The processed data and source code are available in Zenodo:

https://doi.org/10.5281/zenodo.5999705. The source code is also available in GitHub:

https://github.com/SysBioChalmers/TMEModeling.

\section{Funding}

This work was supported by funding from the Knut and Alice Wallenberg foundation (J.N.).

\section{Competing interests}

The authors declare that they have no competing interests.

\section{Authors' contribution}

J.G, J.R, and J.N. planned the project. J.G. and A.H. developed the diffusion model. J.G. wrote all software and made all analyses and figures. J.G. wrote the draft manuscript. All authors reviewed and edited the manuscript. J.R. and J.N. supervised the project. J.N. acquired funding for the project.

\section{Acknowledgements}

We thank Donald Becker for valuable discussions about proline metabolism and Stig Larsson for reviewing the diffusion model. 


\section{References}

1. Forster JC, Harriss-Phillips WM, Douglass MJ, Bezak E. A review of the development of tumor vasculature and its effects on the tumor microenvironment. Hypoxia. 2017;5:21.

2. Nagy JA, Chang S-H, Dvorak AM, Dvorak HF. Why are tumour blood vessels abnormal and why is it important to know? Br J Cancer. 2009 Mar 24;100(6):865-9.

3. Jain RK, Martin JD, Chauhan VP, Duda DG. 8 - Tumor Microenvironment: Vascular and Extravascular Compartment. In: Niederhuber JE, Armitage JO, Kastan MB, Doroshow JH, Tepper JE, editors. Abeloff's Clinical Oncology (Sixth Edition) [Internet]. Philadelphia: Elsevier; 2020 [cited 2021 Dec 9]. p. 108-126.e7. Available from: https://www.sciencedirect.com/science/article/pii/B9780323476744000086

4. Sefidgar M, Soltani M, Raahemifar K, Bazmara H, Nayinian SMM, Bazargan M. Effect of tumor shape, size, and tissue transport properties on drug delivery to solid tumors. J Biol Eng. 2014 Jun $12 ; 8(1): 12$.

5. Busk M, Overgaard J, Horsman MR. Imaging of Tumor Hypoxia for Radiotherapy: Current Status and Future Directions. Semin Nucl Med. 2020 Nov 1;50(6):562-83.

6. Liberti MV, Locasale JW. The Warburg Effect: How Does it Benefit Cancer Cells? Trends Biochem Sci. 2016 Mar;41(3):211-8.

7. Cammann C, Rath A, Reichl U, Lingel H, Brunner-Weinzierl M, Simeoni L, et al. Early changes in the metabolic profile of activated CD8+ T cells. BMC Cell Biol. 2016 Jul 7;17:28.

8. Wise DR, Thompson CB. Glutamine Addiction: A New Therapeutic Target in Cancer. Trends Biochem Sci. 2010 Aug;35(8):427-33.

9. Martinez-Outschoorn UE, Lisanti MP, Sotgia F. Catabolic cancer-associated fibroblasts transfer energy and biomass to anabolic cancer cells, fueling tumor growth. Semin Cancer Biol. 2014 Apr 1;25:47-60.

10. Pavlides S, Whitaker-Menezes D, Castello-Cros R, Flomenberg N, Witkiewicz AK, Frank PG, et al. The reverse Warburg effect: Aerobic glycolysis in cancer associated fibroblasts and the tumor stroma. Cell Cycle. 2009 Dec 1;8(23):3984-4001.

11. Zhao H, Yang L, Baddour J, Achreja A, Bernard V, Moss T, et al. Tumor microenvironment derived exosomes pleiotropically modulate cancer cell metabolism. eLife [Internet]. [cited 2017 Oct 19];5. Available from: https://www.ncbi.nlm.nih.gov/pmc/articles/PMC4841778/

12. Avagliano A, Granato G, Ruocco MR, Romano V, Belviso I, Carfora A, et al. Metabolic Reprogramming of Cancer Associated Fibroblasts: The Slavery of Stromal Fibroblasts. BioMed Res Int. 2018;2018:6075403.

13. Orth JD, Thiele I, Palsson $B \varnothing$. What is flux balance analysis? Nat Biotechnol. 2010 Mar;28(3):245-8.

14. Nilsson A, Björnson E, Flockhart M, Larsen FJ, Nielsen J. Complex I is bypassed during high intensity exercise. Nat Commun. 2019 Nov 7;10(1):5072. 
bioRxiv preprint doi: https://doi.org/10.1101/2022.02 08.479584 this version posted February 10 2022. The copyright holder for this preprint (which was not certified by peer review) is the author/funder, who has granted bioRxiv a license to display the preprint in perpetuity. It is made available under aCC-BY 4.0 International license.

15. Nilsson A, Haanstra JR, Engqvist M, Gerding A, Bakker BM, Klingmüller U, et al. Quantitative analysis of amino acid metabolism in liver cancer links glutamate excretion to nucleotide synthesis. Proc Natl Acad Sci [Internet]. 2020 Apr 27 [cited 2020 May 7]; Available from: https://www.pnas.org/content/early/2020/04/24/1919250117

16. Wang H, Robinson JL, Kocabas P, Gustafsson J, Anton M, Cholley P-E, et al. Genome-scale metabolic network reconstruction of model animals as a platform for translational research. Proc Natl Acad Sci [Internet]. 2021 Jul 27 [cited 2021 Jul 19];118(30). Available from: https://www.pnas.org/content/118/30/e2102344118

17. Sánchez BJ, Zhang C, Nilsson A, Lahtvee P-J, Kerkhoven EJ, Nielsen J. Improving the phenotype predictions of a yeast genome-scale metabolic model by incorporating enzymatic constraints. Mol Syst Biol. 2017 Aug 1;13(8):935.

18. Jain M, Nilsson R, Sharma S, Madhusudhan N, Kitami T, Souza AL, et al. Metabolite profiling identifies a key role for glycine in rapid cancer cell proliferation. Science. 2012 May 25;336(6084):1040-4.

19. Hui S, Ghergurovich JM, Morscher RJ, Jang C, Teng X, Lu W, et al. Glucose feeds the TCA cycle via circulating lactate. Nature. 2017 Nov;551(7678):115-8.

20. Robinson JL, Kocabaş P, Wang H, Cholley P-E, Cook D, Nilsson A, et al. An atlas of human metabolism. Sci Signal [Internet]. 2020 Mar 24 [cited 2020 Mar 28];13(624). Available from: https://stke.sciencemag.org/content/13/624/eaaz1482

21. Opdam S, Richelle A, Kellman B, Li S, Zielinski DC, Lewis NE. A Systematic Evaluation of Methods for Tailoring Genome-Scale Metabolic Models. Cell Syst. 2017 Mar 22;4(3):318329.e6.

22. Kilburn DG, Lilly MD, Webb FC. The Energetics of Mammalian Cell Growth. J Cell Sci. 1969 May $1 ; 4(3): 645-54$.

23. Domenzain I, Sánchez B, Anton M, Kerkhoven EJ, Millán-Oropeza A, Henry C, et al. Reconstruction of a catalogue of genome-scale metabolic models with enzymatic constraints using GECKO 2.0. bioRxiv. 2021 Mar 5;2021.03.05.433259.

24. Chang A, Jeske L, Ulbrich S, Hofmann J, Koblitz J, Schomburg I, et al. BRENDA, the ELIXIR core data resource in 2021: new developments and updates. Nucleic Acids Res. 2021 Jan 8;49(D1):D498-508.

25. Liu D, Chalkidou A, Landau DB, Marsden PK, Fenwick JD. Interstitial diffusion and the relationship between compartment modelling and multi-scale spatial-temporal modelling of ${ }^{18}$ F-FLT tumour uptake dynamics. Phys Med Biol. 2014 Sep 7;59(17):5175-202.

26. Harada S, Hirayama A, Chan Q, Kurihara A, Fukai K, lida M, et al. Reliability of plasma polar metabolite concentrations in a large-scale cohort study using capillary electrophoresis-mass spectrometry. PLOS ONE. 2018 Jan;13(1):e0191230.

27. Hoogenboezem EN, Duvall CL. Harnessing Albumin as a Carrier for Cancer Therapies. Adv Drug Deliv Rev. 2018 May;130:73-89. 
bioRxiv preprint doi: https:/doi org/10.1101/2022.02.08.479584; this version posted February 10 2022. The copyright holder for this preprint (which was not certified by peer review) is the author/funder, who has granted bioRxiv a license to display the preprint in perpetuity. It is made available under aCC-BY 4.0 International license.

28. Quehenberger O, Armando AM, Brown AH, Milne SB, Myers DS, Merrill AH, et al. Lipidomics reveals a remarkable diversity of lipids in human plasma1[S]. J Lipid Res. 2010 Nov 1;51(11):3299-305.

29. Siggaard-andersen $\mathrm{O}$, Gøthgen IH, Wimberley PD, Fogh-andersen N. The oxygen status of the arterial blood revised: Relevant oxygen parameters for monitoring the arterial oxygen availability. Scand J Clin Lab Invest. 1990 Jan 1;50(sup203):17-28.

30. Zhang X, Li C-G, Ye C-H, Liu M-L. Determination of Molecular Self-Diffusion Coefficient Using Multiple Spin-Echo NMR Spectroscopy with Removal of Convection and Background Gradient Artifacts. Anal Chem. 2001 Aug 1;73(15):3528-34.

31. Chary SR, Jain RK. Direct measurement of interstitial convection and diffusion of albumin in normal and neoplastic tissues by fluorescence photobleaching. Proc Natl Acad Sci. $1989 \mathrm{Jul}$ 1;86(14):5385-9.

32. Goldstick TK, Ciuryla VT, Zuckerman L. Diffusion of oxygen in plasma and blood. Adv Exp Med Biol. 1976;75:183-90.

33. Valencia DP, González FJ. Estimation of diffusion coefficients by using a linear correlation between the diffusion coefficient and molecular weight. J Electroanal Chem. 2012 Aug 1;681:121-6.

34. Fan J, Kamphorst JJ, Mathew R, Chung MK, White E, Shlomi T, et al. Glutamine-driven oxidative phosphorylation is a major ATP source in transformed mammalian cells in both normoxia and hypoxia. Mol Syst Biol. 2013 Jan 1;9(1):712.

35. Tabata S, Yamamoto M, Goto H, Hirayama A, Ohishi M, Kuramoto T, et al. Thymidine Catabolism as a Metabolic Strategy for Cancer Survival. Cell Rep. 2017 May 16;19(7):1313-21.

36. Seidlitz EP, Sharma MK, Saikali Z, Ghert M, Singh G. Cancer cell lines release glutamate into the extracellular environment. Clin Exp Metastasis. 2009;26(7):781-7.

37. Takano T, Lin JH-C, Arcuino G, Gao Q, Yang J, Nedergaard M. Glutamate release promotes growth of malignant gliomas. Nat Med. 2001 Sep;7(9):1010-5.

38. Lange F, Hörnschemeyer J, Kirschstein T. Glutamatergic Mechanisms in Glioblastoma and Tumor-Associated Epilepsy. Cells. 2021 May 17;10(5):1226.

39. Chinopoulos C, Seyfried TN. Mitochondrial Substrate-Level Phosphorylation as Energy Source for Glioblastoma: Review and Hypothesis. ASN Neuro. 2018 Jan 1;10:1759091418818261.

40. Wang Y, Bai C, Ruan Y, Liu M, Chu Q, Qiu L, et al. Coordinative metabolism of glutamine carbon and nitrogen in proliferating cancer cells under hypoxia. Nat Commun. 2019 Jan 14;10(1):201.

41. Corbet C, Feron O. Tumour acidosis: from the passenger to the driver's seat. Nat Rev Cancer. 2017 Oct;17(10):577-93.

42. Garcia-Bermudez J, Baudrier L, La K, Zhu XG, Fidelin J, Sviderskiy VO, et al. Aspartate is a limiting metabolite for cancer cell proliferation under hypoxia and in tumours. Nat Cell Biol. 2018 Jul;20(7):775-81. 
bioRxiv preprint doi: https://doi.org/10.1101/2022.02 08.479584 this version posted February 10 2022. The copyright holder for this preprint (which was not certified by peer review) is the author/funder, who has granted bioRxiv a license to display the preprint in perpetuity. It is made available under aCC-BY 4.0 International license.

43. Quinlan CL, Orr AL, Perevoshchikova IV, Treberg JR, Ackrell BA, Brand MD. Mitochondrial Complex II Can Generate Reactive Oxygen Species at High Rates in Both the Forward and Reverse Reactions*. J Biol Chem. 2012 Aug 3;287(32):27255-64.

44. Jung JG, Le A. Targeting Metabolic Cross Talk Between Cancer Cells and Cancer-Associated Fibroblasts. In: Le A, editor. The Heterogeneity of Cancer Metabolism [Internet]. Cham: Springer International Publishing; 2021 [cited 2021 Aug 17]. p. 205-14. (Advances in Experimental Medicine and Biology). Available from: https://doi.org/10.1007/978-3-03065768-0_15

45. Sousa CM, Biancur DE, Wang X, Halbrook CJ, Sherman MH, Zhang L, et al. Pancreatic stellate cells support tumour metabolism through autophagic alanine secretion. Nature. 2016 Aug;536(7617):479-83.

46. Capparelli C, Guido C, Whitaker-Menezes D, Bonuccelli G, Balliet R, Pestell TG, et al. Autophagy and senescence in cancer-associated fibroblasts metabolically supports tumor growth and metastasis, via glycolysis and ketone production. Cell Cycle. 2012 Jun 15;11(12):2285-302.

47. Vitale I, Manic G, Coussens LM, Kroemer G, Galluzzi L. Macrophages and Metabolism in the Tumor Microenvironment. Cell Metab. 2019 Jul 2;30(1):36-50.

48. Lin Y, Xu J, Lan H. Tumor-associated macrophages in tumor metastasis: biological roles and clinical therapeutic applications. J Hematol OncolJ Hematol Oncol. 2019 Jul 12;12(1):76.

49. Sonveaux P, Végran F, Schroeder T, Wergin MC, Verrax J, Rabbani ZN, et al. Targeting lactatefueled respiration selectively kills hypoxic tumor cells in mice. J Clin Invest. 2008 Dec 1;118(12):3930-42.

50. de la Cruz-López KG, Castro-Muñoz L, Reyes-Hernández DO, García-Carrancá A, Manzo-Merino J. Lactate in the Regulation of Tumor Microenvironment and Therapeutic Approaches. Front Oncol. 2019 Nov 1;9:1143.

51. Swietach P, Vaughan-Jones RD, Harris AL, Hulikova A. The chemistry, physiology and pathology of pH in cancer. Philos Trans R Soc B Biol Sci. 2014 Mar 19;369(1638):20130099.

52. Estrella V, Chen T, Lloyd M, Wojtkowiak J, Cornnell HH, Ibrahim-Hashim A, et al. Acidity Generated by the Tumor Microenvironment Drives Local Invasion. Cancer Res. 2013 Mar $1 ; 73(5): 1524-35$.

53. Vaughan-Jones RD, Wu ML. Extracellular $\mathrm{H}+$ inactivation of $\mathrm{Na}(+)-\mathrm{H}+$ exchange in the sheep cardiac Purkinje fibre. J Physiol. 1990 Sep;428:441-66.

54. Wang H, Marcišauskas S, Sánchez BJ, Domenzain I, Hermansson D, Agren R, et al. RAVEN 2.0: A versatile toolbox for metabolic network reconstruction and a case study on Streptomyces coelicolor. PLOS Comput Biol. 2018 okt;14(10):e1006541. 


\title{
Supplementary information
}

\section{Cellular limitation of enzymatic capacity explains glutamine addiction in cancers}

\author{
Johan Gustafsson ${ }^{1,2}$, Fariba Roshanzamir ${ }^{1}$, Anders Hagnestål ${ }^{3}$, Jonathan L. Robinson ${ }^{1,4}$, Jens \\ Nielsen ${ }^{1,2,4, *}$ \\ ${ }^{1}$ Department of Biology and Biological Engineering, Chalmers University of Technology, Gothenburg, Sweden. \\ ${ }^{2}$ Wallenberg Center for Protein Research, Chalmers University of Technology, Gothenburg, Sweden. \\ ${ }^{3}$ Hagnesia $A B$, Hindås, Sweden \\ ${ }^{4}$ Biolnnovation Institute, Copenhagen, Denmark \\ * Corresponding author \\ E-mail: nielsenj@chalmers.se
}




\section{Supplementary Figures}

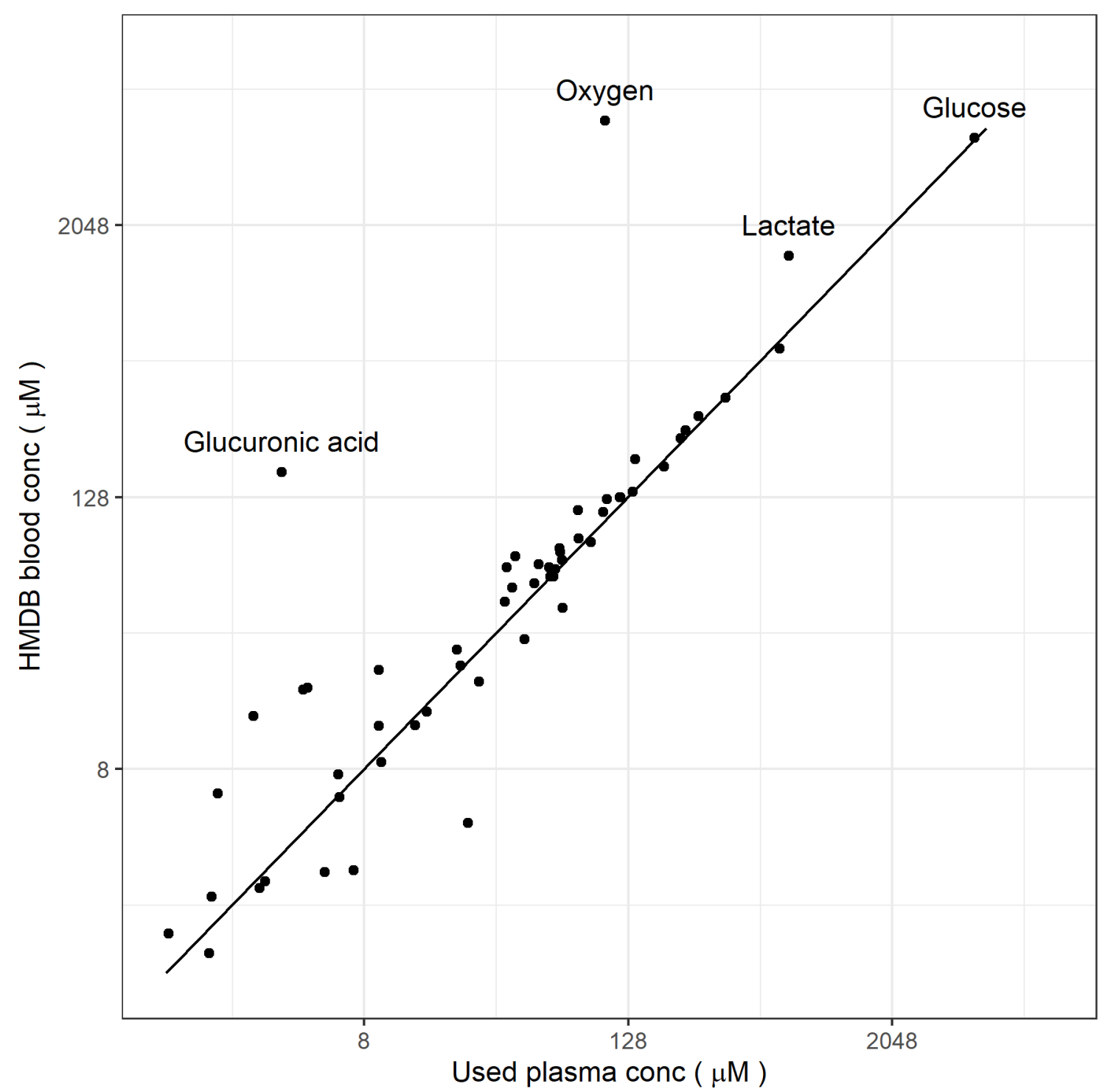

Fig S1: Validation of used blood plasma metabolite concentrations. The figure shows a comparison between HMDB $(1,2)$ and the data from Akinci et al (for glucose, HMDB value used in simulations), Siggaard-Andersen et al (for oxygen), and Harada et al (3-5). The line shows the ideal relationship between the data sources, it is not a linear fit to the points. Only metabolites with data from both sources where the metabolite name could be mapped to the model are shown. 


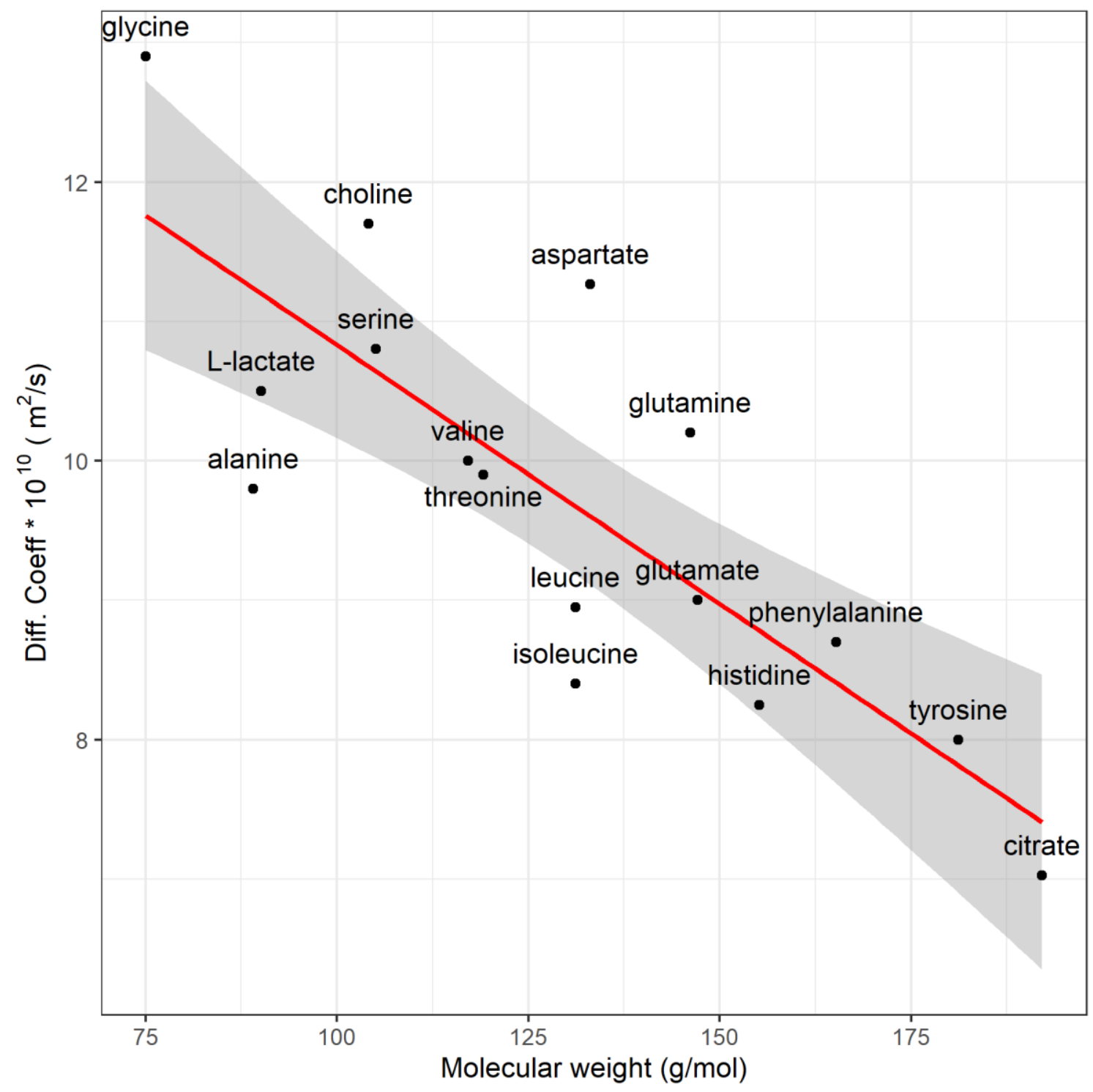

Fig. S2: Linear model for estimation of diffusion coefficients from molecular mass. The model is used to estimate the diffusion coefficients for metabolites where no such value is available. Oxygen and albumin are not included in the model since a linear model is only valid within a limited molecular mass range. 
bioRxiv preprint doi: https://doi.org/10.1101/2022 02 08.479584 this version posted February 10 2022. The copyright holder for this preprint (which was not certified by peer review) is the author/funder, who has granted bioRxiv a license to display the preprint in perpetuity. It is made available under aCC-BY 4.0 International license.

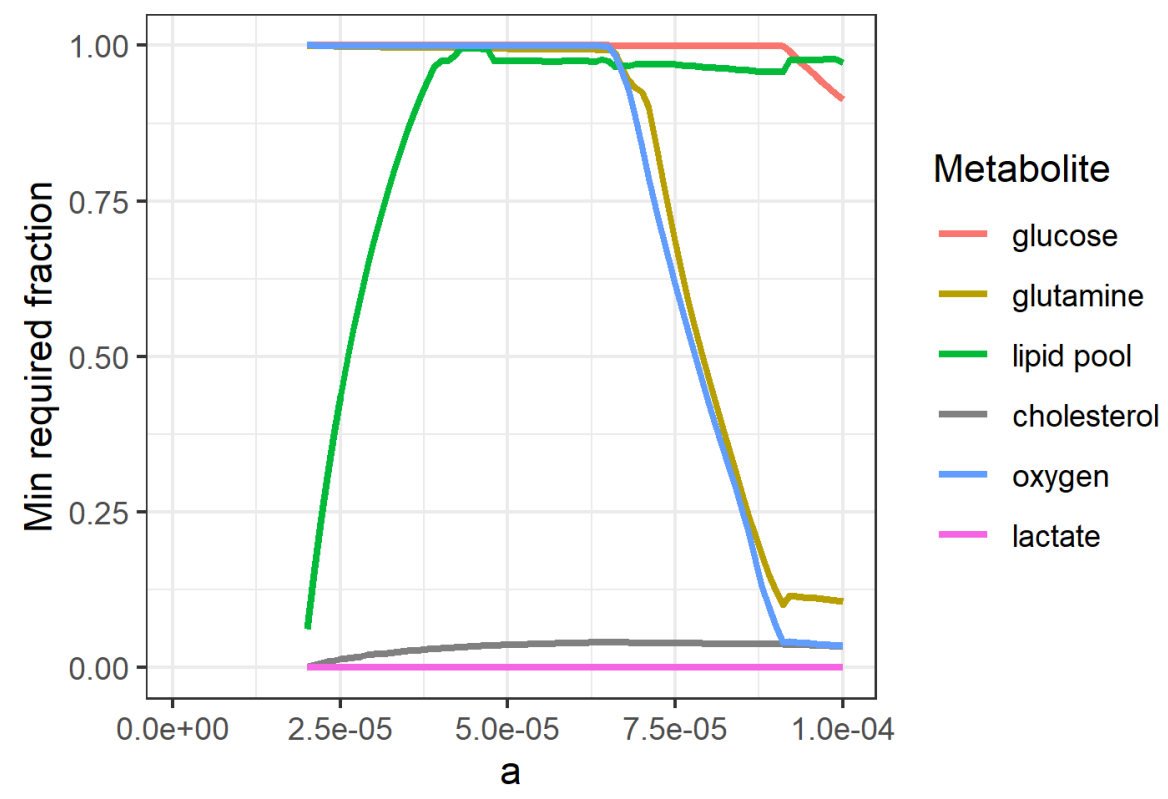

Fig. S3: Growth limitation of metabolites when simulating tumor cell growth. Investigation of which metabolites are limiting for growth at different values of a. The simulation is performed by fixing the specific growth rate at the maximum possible specific growth rate, followed by a minimization of the uptake of a specific metabolite (FVA). The "min required fraction" represents the minimum required uptake rate of the metabolite divided by the maximal possible value - a value of 1 thus represents that a metabolite is limiting for growth. 
bioRxiv preprint doi: https://doi.org/10.1101/2022.02 08.479584; this version posted February 10 2022. The copyright holder for this preprint (which was not certified by peer review) is the author/funder, who has granted bioRxiv a license to display the preprint in perpetuity. It is made available under aCC-BY 4.0 International license.

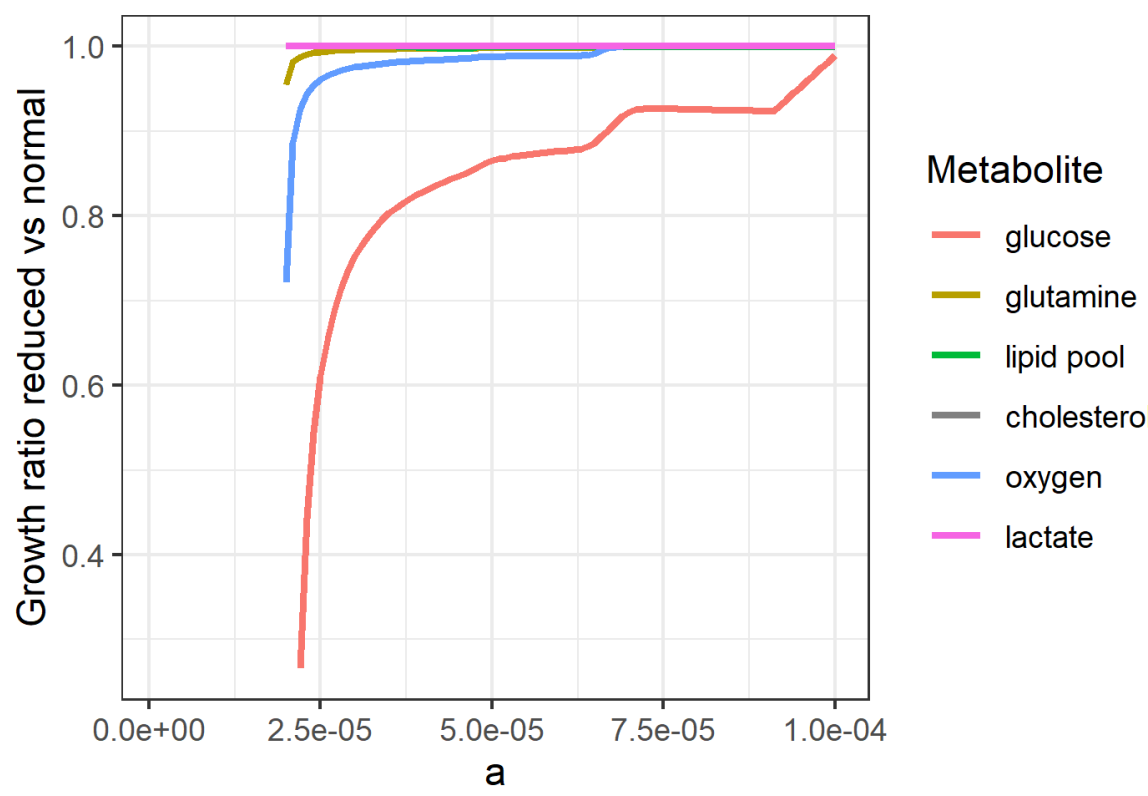

Fig. S4: Growth dependence of metabolites. The simulated specific growth rate of the model is compared to that when the maximum uptake rate of a single metabolite is reduced to $90 \%$. 


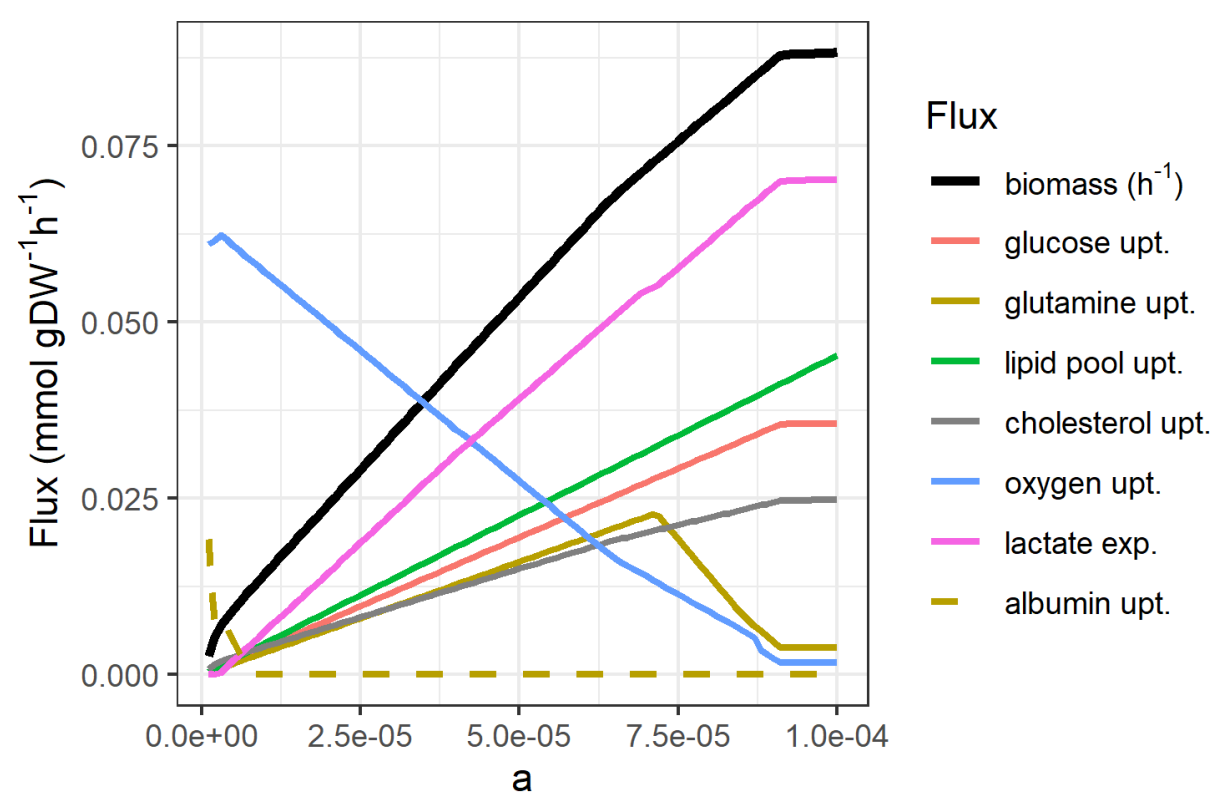

Fig. S5: Simulation of tumor cell growth without oxygen constraints. Identical to the simulation in Fig. $1 B$ in the main text except that oxygen uptake is unconstrained. Albumin uptake is also added to the figure. The albumin uptake rate is multiplied by 200 to fit the scale of the other fluxes, while other metabolites are scaled the same way as in Fig. $1 B$ in the main text. Albumin was useful for growth at small a values since enzyme usage was not limited at such a values, allowing for full oxidation of the amino acids for the purpose of ATP generation, which overcomes the ATP cost associated with digestion of albumin into amino acids. 


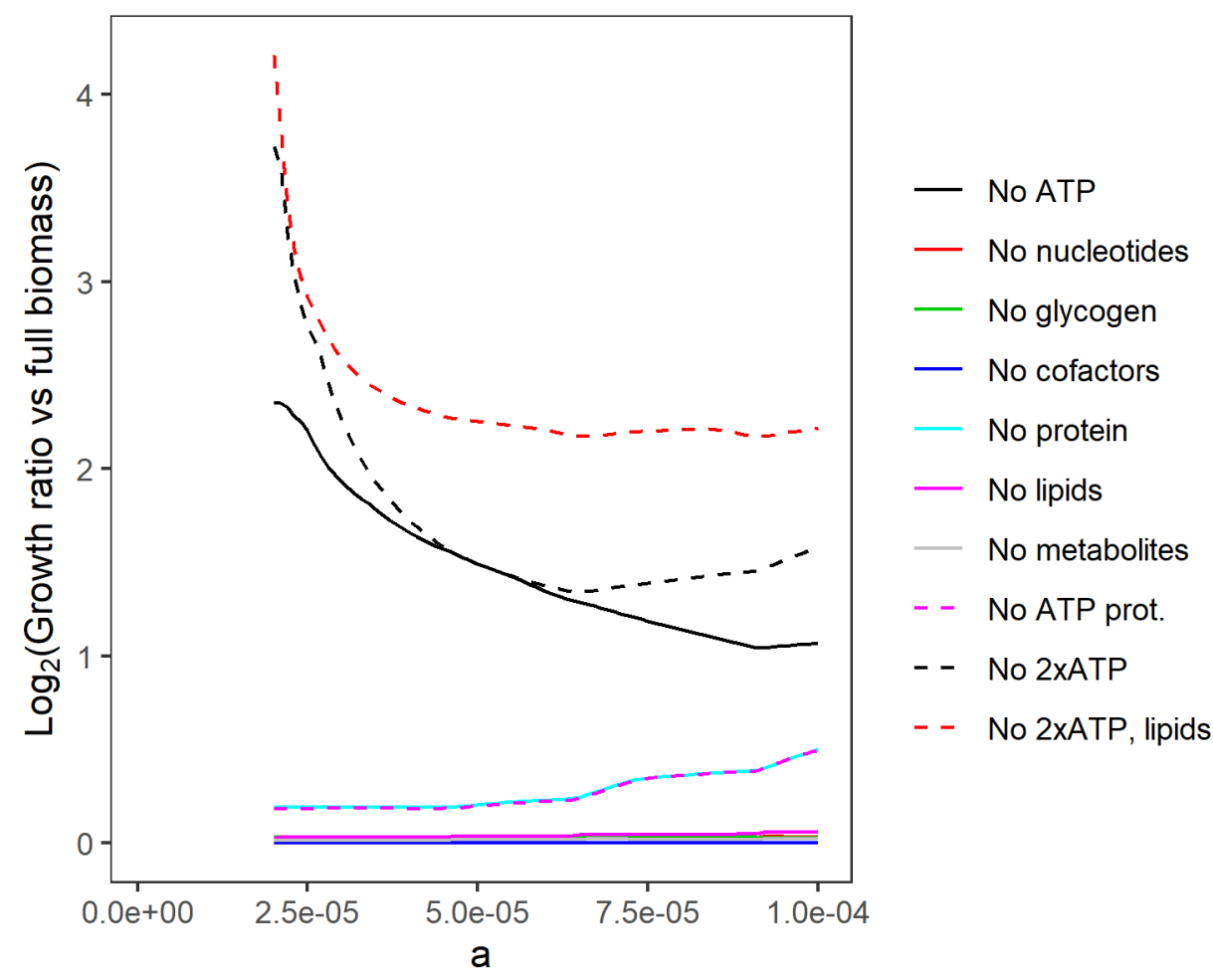

Fig S6: Change in specific growth rate when removing parts of the biomass reaction. The figure shows the specific growth rate ratio between models with reduced and original biomass reaction. In all cases, the model is optimized for growth. "No ATP prot." refers to removal of the ATP cost from turning amino acids into proteins, while "No 2XATP" refers to having both the protein generation ATP cost and the direct ATP cost removed from the biomass reaction. For "No 2xATP, lipids", the consumption of lipids have also been removed in addition to the other two factors. ATP generation is the limiting factor for all values of a. With ATP costs removed, the availability of lipids became limiting, while the direct use of amino acids for protein synthesis was small compared to the amounts available. 
bioRxiv preprint doi: https://doi.org/10.1101/2022.02 08.479584; this version posted February 10 2022. The copyright holder for this preprint (which was not certified by peer review) is the author/funder, who has granted bioRxiv a license to display the preprint in perpetuity. It is made available under aCC-BY 4.0 International license.

A

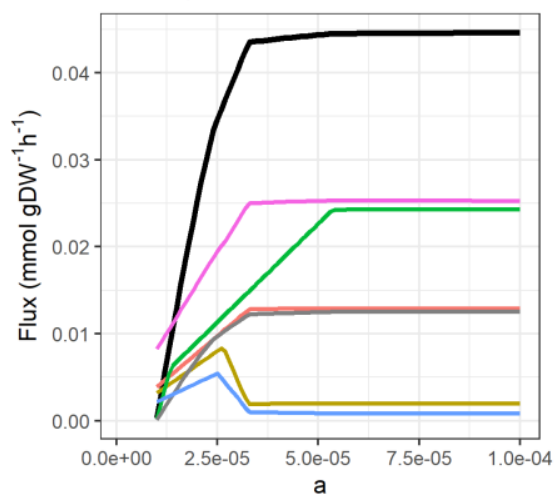

C Growth limitation, 0.5 ATP

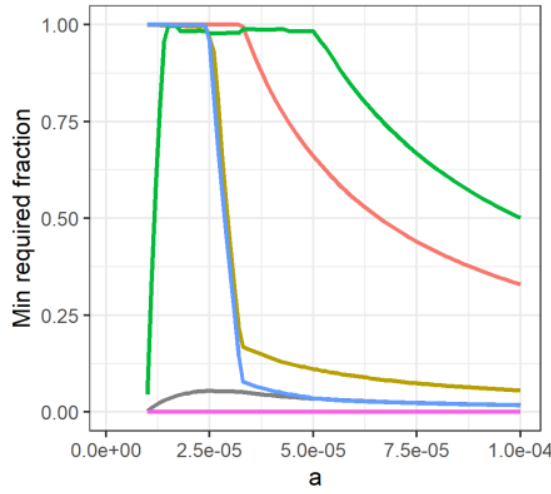

E Met. reduction, 0.5 ATP

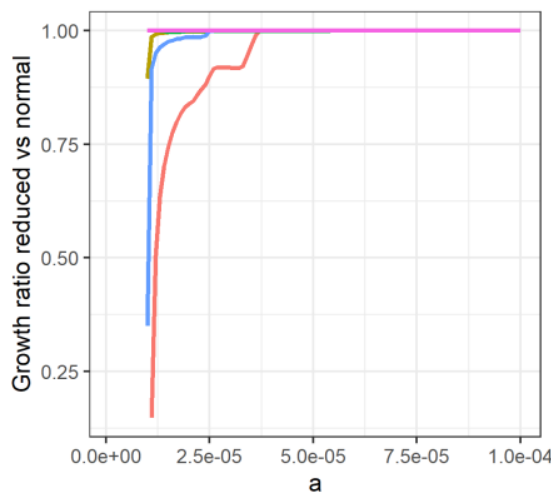

Flux

- biomass $\left(\mathrm{h}^{-1}\right)$

- glucose upt.

- glutamine upt.

- lipid pool upt.

- cholesterol upt

- oxygen upt.

- lactate exp.

Metabolite

- glucose

- glutamine

— lipid pool

— cholesterol

- oxygen

- lactate

Metabolite

- glucose

- glutamine

- lipid pool

- cholesterol

- oxygen

- lactate
B

Fluxes, 0.25 ATP

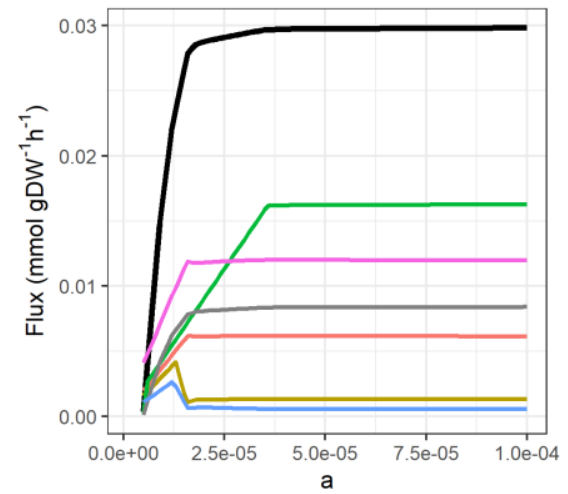

Flux

- biomass $\left(\mathrm{h}^{-1}\right)$

- glucose upt.

- glutamine upt.

- lipid pool upt.

- cholesterol upt

- oxygen upt.

- lactate exp.

D Growth limitation, 0.25 ATP

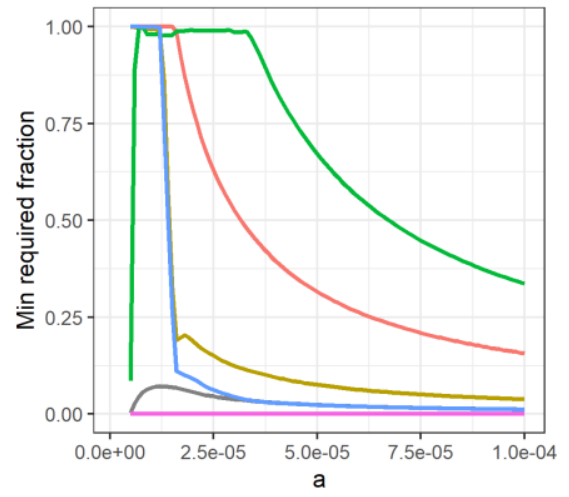

Metabolite

- glucose

- glutamine

- lipid pool

- cholesterol

- oxygen

- lactate

Fig S7: Metabolites limiting for growth when the direct ATP cost of the biomass function and NGAM are reduced to $50 \%$ and $25 \%$ of the original values. $A-B$ : Specific growth rate and metabolite uptake/export. C-D: Flux variability analysis showing how much each metabolite can be reduced while retaining growth. E-F: Specific growth rate reduction from reducing the maximum uptake rate of a single metabolite to $90 \%$.

F Met. reduction, 0.25 ATP

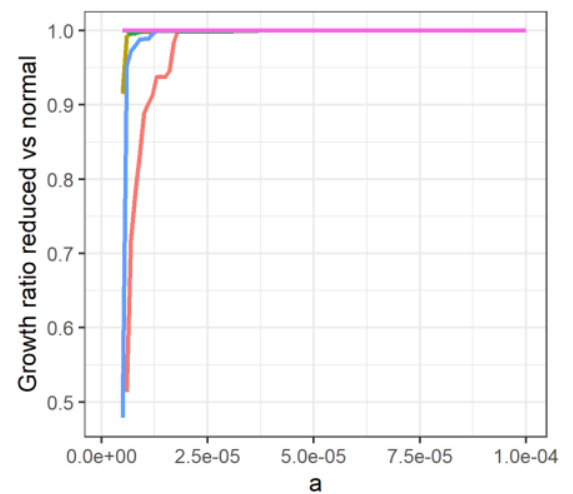

Metabolite

- glucose

- glutamine

- lipid pool

- cholesterol

- oxygen

- lactate 
bioRxiv preprint doi: https://doi.org/10.1101/2022.02 08.479584; this version posted February 10 2022. The copyright holder for this preprint (which was not certified by peer review) is the author/funder, who has granted bioRxiv a license to display the preprint in perpetuity. It is made available under aCC-BY 4.0 International license.

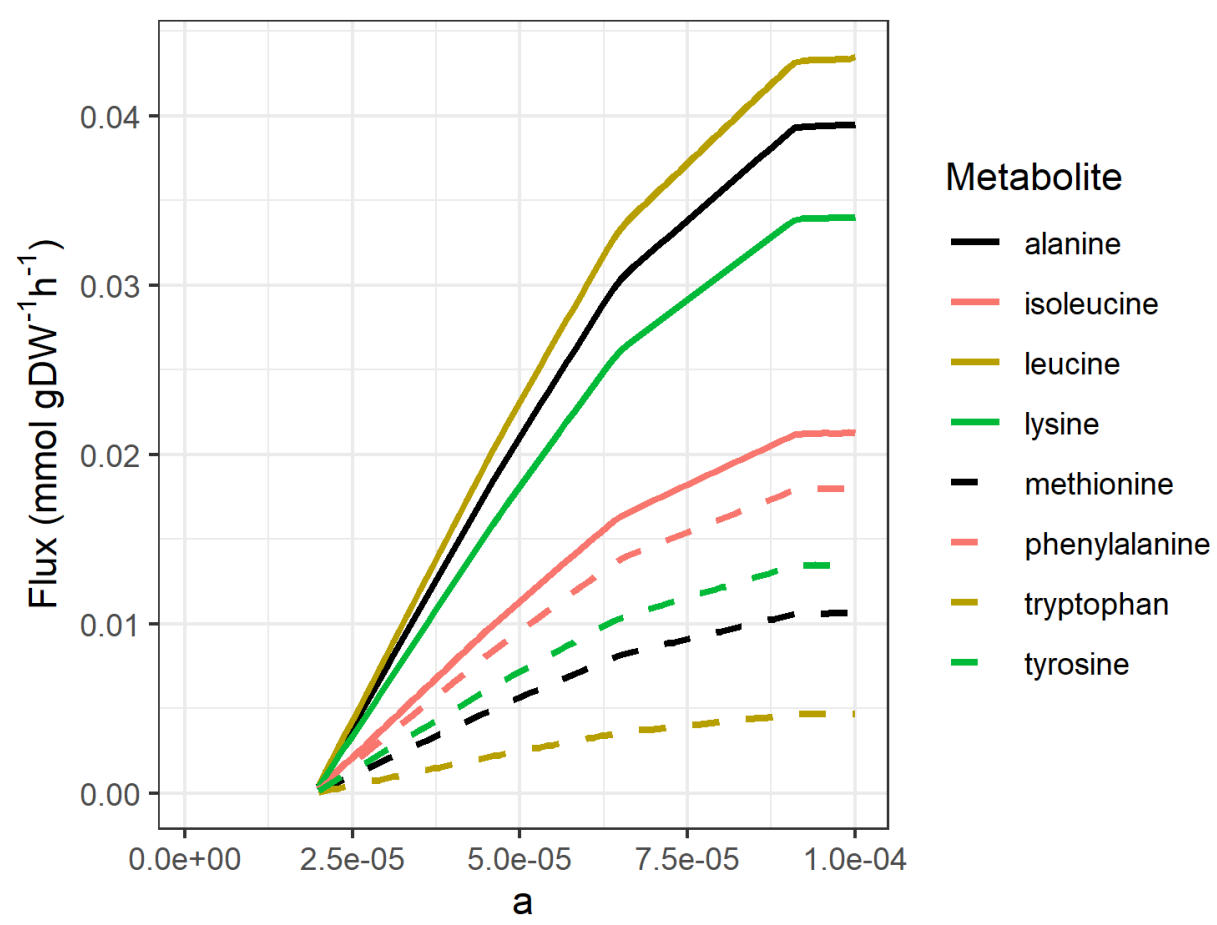

Fig S8: Uptake of amino acids not used for ATP production in the tumor microenvironment simulation. This figure shows the uptake of amino acids that are mainly used for protein production in a simulation of tumor cell growth with metabolite uptake constraints derived from the diffusion model. The figure is similar to Fig. $2 A$ and $B$ in the main text. 
bioRxiv preprint doi: https://doi.org/10.1101/2022.02.08.479584; this version posted February 10,2022 . The copyright holder for this preprint (which was not certified by peer review) is the author/funder, who has granted bioRxiv a license to display the preprint in perpetuity. It is made available under aCC-BY 4.0 International license.

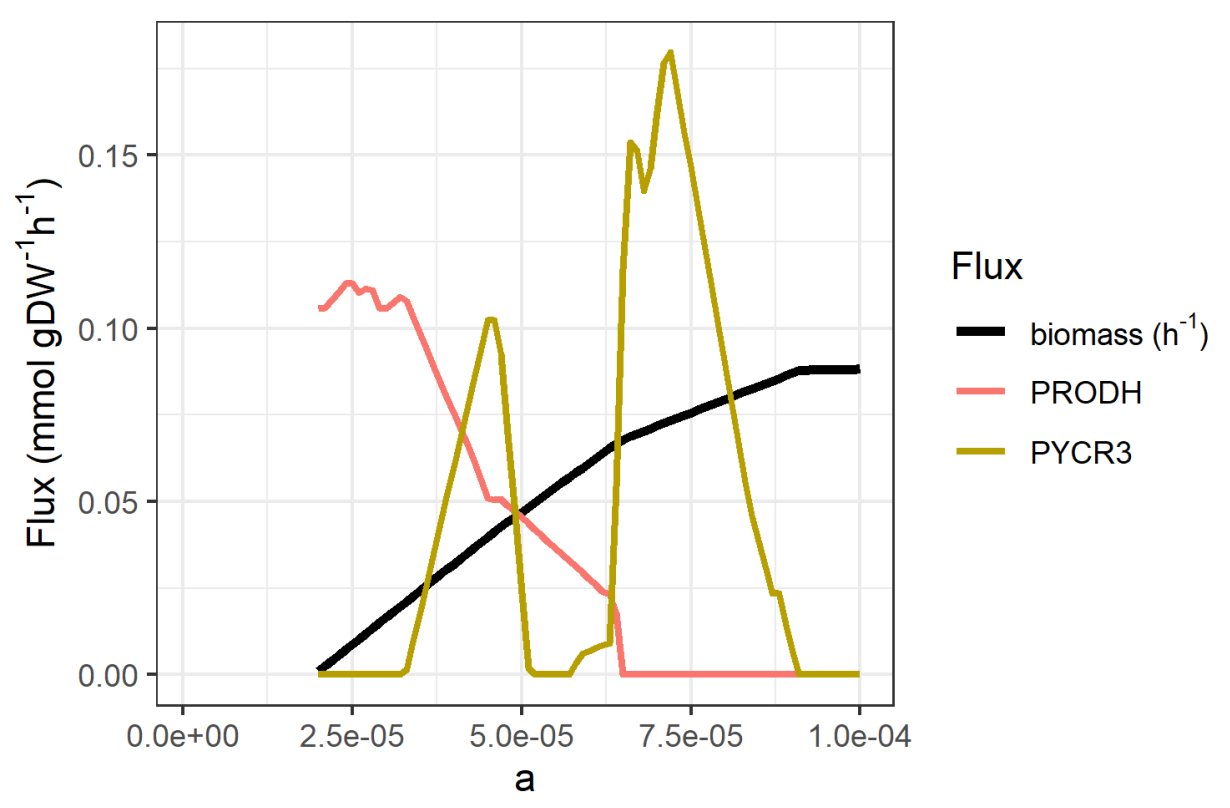

Fig S9: Fluxes of the two proline pathways used by the model for increasing growth. 
bioRxiv preprint doi: https://doi.org/10.1101/2022.02 08.479584 this version posted February 10 2022. The copyright holder for this preprint (which was not certified by peer review) is the author/funder, who has granted bioRxiv a license to display the preprint in perpetuity. It is made available under aCC-BY 4.0 International license.

A Hypoxic

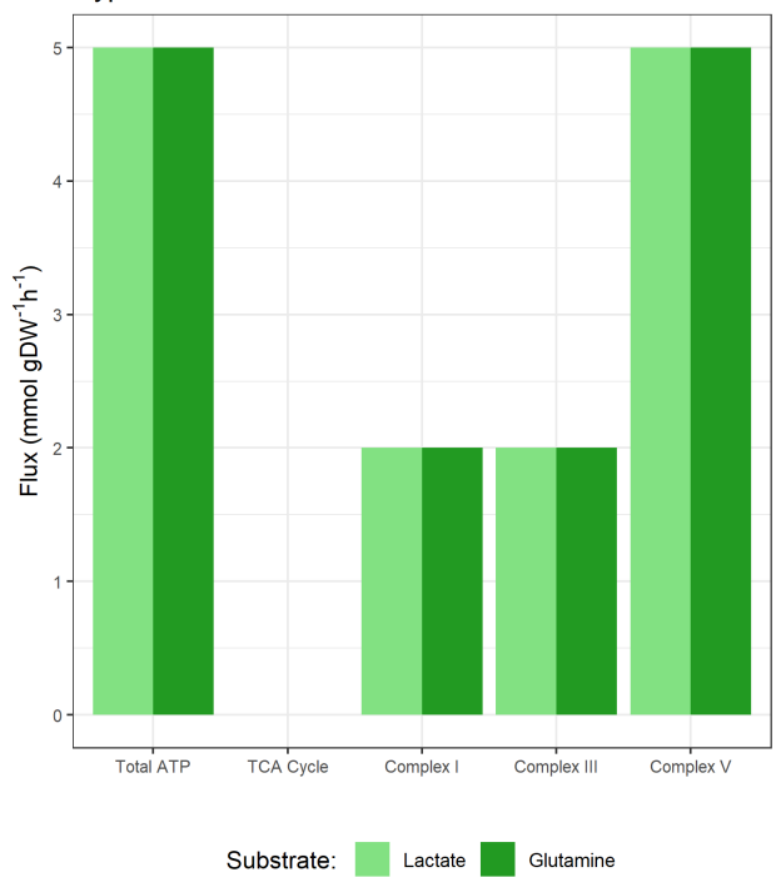

B Enzyme-limited

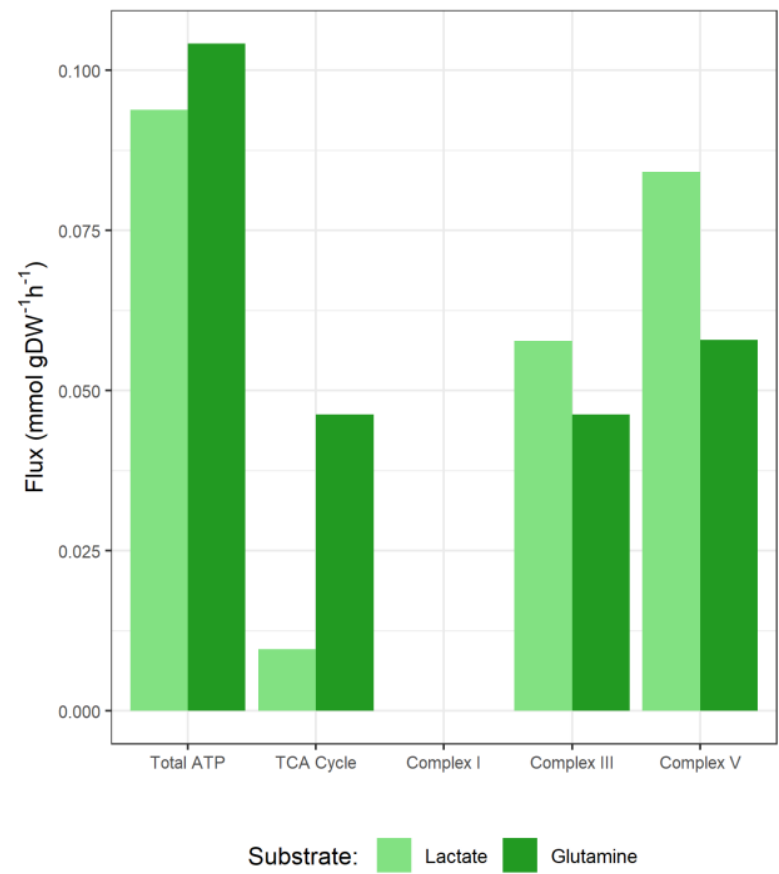

Fig S10: Differences in ATP production from the substrates lactate and glutamine. A. Hypoxic conditions with the reverse PRODH reaction blocked. B. Enzyme-limited conditions. 

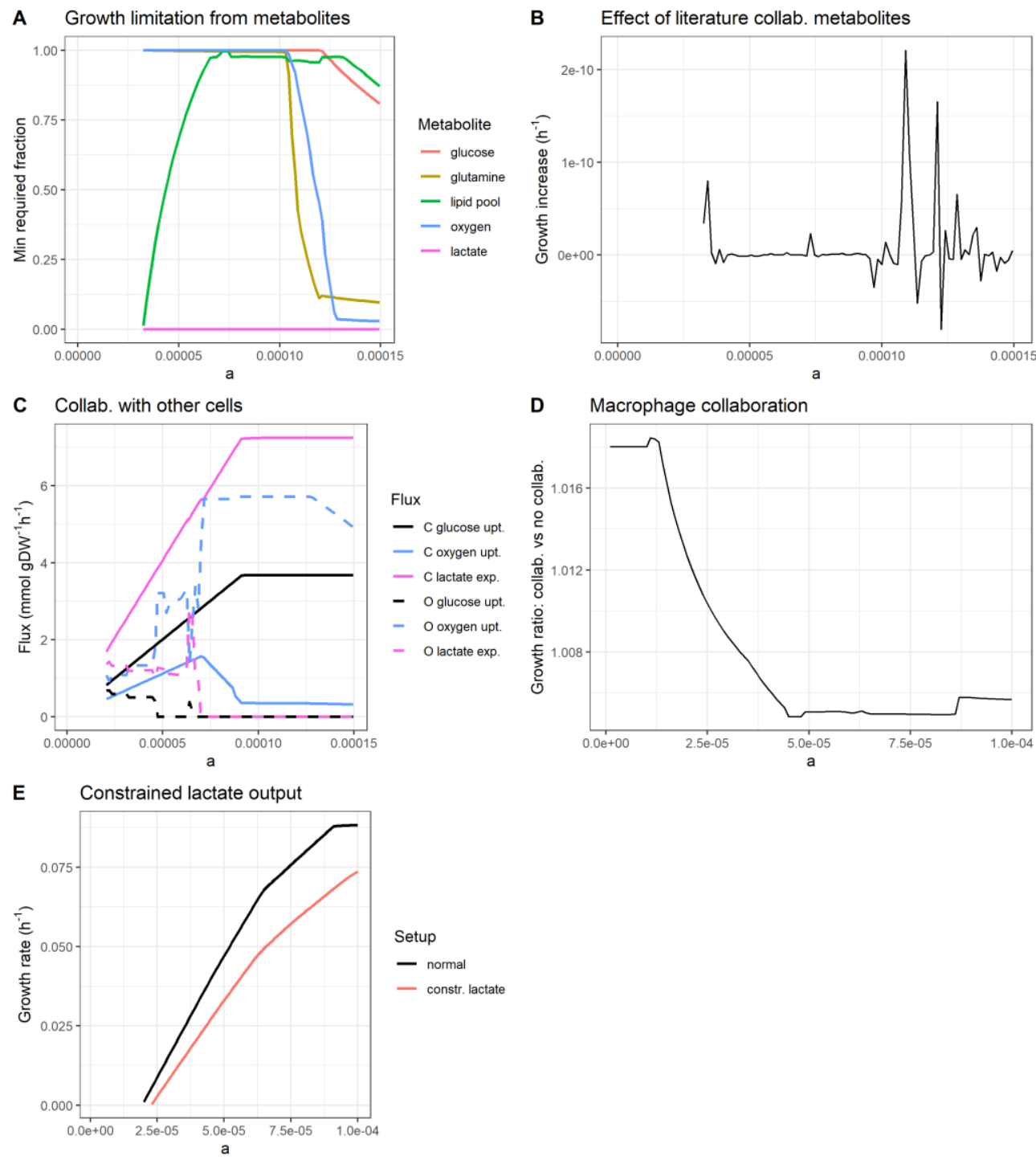

Fig. S11: Additional plots for the combined model. A. Investigation of which metabolites are limiting for growth at different values of a for the $\mathrm{m} 3$ model, which has a high ECM content. The simulation is performed by fixing the specific growth rate at the maximum possible specific growth rate, followed by a minimization of the uptake of a specific metabolite. The min required fraction represents the minimum required uptake rate of the metabolite divided by the maximal possible value - a value close to 1 thus represents that a metabolite is limiting for growth. B. Maximum increase in specific growth rate by collaboration with CAFs allowing only metabolites previously identified in literature to be sent from the CAFs to the tumor cells. C. Metabolite uptake rates in a passive collaboration between cancer cells and other cells. The $m 6$ model is used, which has negligible fractions of both fibroblasts and ECM, and only a small fraction of other cells, which due to the low availability of oxygen is beneficial for showing shifts in oxygen use between cell types for different values of $a$. The simulation shows the expected behavior; the other cells consume little glucose while instead consuming the metabolites that are least useful for the cancer cells. These are a large pool of compounds such as citrate and linoleate together with oxygen and are used to generate the maintenance ATP needed to sustain the cells. D. Maximum increase in specific growth rate by collaboration with macrophages that reuse $10 \%$ of the produced biomass (dead cells). E. Effect on specific growth rate by of constraining the lactate export flux to half of the maximum glucose uptake flux. 


\section{Supplementary Tables}

Table S1 - Additional blood metabolite candidates from HMDB Available as a separate Excel sheet.

Table S2 - Metabolites from HMDB that could not be mapped to the model

Available as a separate Excel sheet.

Table S3 - Consensus metabolite concentrations in blood and corresponding diffusion coefficients

Available as a separate Excel sheet.

Table S4 - Potential collaboration metabolites between fibroblasts and tumor cells

Available as a separate Excel sheet.

Table S5 - Additional metabolite availability from dead cells Available as a separate Excel sheet. 


\section{Table S6 - Reactions blocked in Human1 for the simulations}

The following reactions were blocked in Human1 as a curation step since they gave rise to unrealistic fluxes.

\begin{tabular}{|l|}
\hline Blocked reactions \\
\hline MAR08759 \\
\hline MAR02779_REV \\
\hline MAR03996 \\
\hline MAR06965 \\
\hline MAR13081 \\
\hline MAR08981 \\
\hline MAR03167 \\
\hline MAR12019 \\
\hline MAR01706 \\
\hline MAR08561 \\
\hline MAR07701 \\
\hline MAR01575 \\
\hline MAR04423 \\
\hline MAR08606 \\
\hline MAR00059 \\
\hline MAR07703 \\
\hline MAR07706 \\
\hline MAR06539 \\
\hline MAR06606 \\
\hline MAR06611 \\
\hline MAR08017 \\
\hline MAR08021 \\
\hline MAR05390 \\
\hline MAR06770 \\
\hline MAR07647 \\
\hline
\end{tabular}




\section{Supplementary notes}

\section{Supplementary note 1 - GECKO Light}

GECKO Light is based on strategies previously developed and implemented in GECKO Toolbox $(6,7)$, but with the aim to produce minimal models, similarly to what has been done in SMOMENT (8). A metabolite "prot_pool" is added to the model, and each reaction associated with an enzyme cost consumes this metabolite. The stoichiometric coefficient $N$ is calculated as

$$
N=\frac{\sum_{i} M_{w, i}}{k_{\text {cat }}}
$$

where $M_{w, i}$ is the molecular weight of part $i$ in the complex, where non-complex enzymes are treated as a complex with just one part and $k_{\text {cat }}$ represents the catalytic efficiency of the enzyme. In cases where several isozymes convey the same reaction, the stoichiometric coefficient of the isozyme with the lowest protein cost is used.

Reactions with empty gene rules are assigned a standard protein cost (the median over all stoichiometric coefficients for "prot_pool" set in the model). Exchange reactions and transport reactions only involving a single metabolite are excluded, as well as reactions marked as spontaneous in Human1.

To hinder poorly matched outlier kcats from dominating the simulation, GECKO Light fills in a standard protein cost for reactions with missing gene rules and corrects unrealistically low $k_{\text {cat }}$ values by not allowing values below a certain value $\left(1 \mathrm{~s}^{-1}\right)$. This value is of the same order of magnitude as the $k_{\text {cat }}$ of the rubisco enzyme, known to be a particularly slow enzyme (9).

A constrained exchange reaction of the "prot_pool" metabolite (called "prot_pool_exchange") is also added to the model. The constraint on the total metabolic enzyme usage was fit to experimental values of 11 cell lines from $\mathrm{NCl}-60$ for which the specific growth rate and metabolite uptake rates were deemed reliable (10-12), resulting in a value of $0.022 \mathrm{~g} / \mathrm{gDW}$. 


\section{Supplementary note 2 - diffusion model}

It is challenging to accurately model and quantify the maximum absolute fluxes of metabolites from the blood stream into the tumor. These fluxes depend on many parameters, such as capillary permeability and the geometry of the tumor and blood vessels. A more practical approach is to instead try to quantify the fluxes of metabolites relative to those of other metabolites, which can be useful for estimating which metabolites are potentially in short supply and thereby limiting for tumor growth. We assume a model where the influx of metabolites from the blood to the tumor is driven by diffusion.

The diffusion process is modeled axisymmetrically in two dimensions with radial flux out from the capillary wall, assuming that the capillary is long and that we therefore have no net flux along the capillary (Fig A). In steady state, we assume a fixed concentration of each metabolite just outside the capillary wall, which is proportional to its concentration in the blood $\left(c_{b}\right)$. While it is hard to estimate the permeability of the blood vessel, such an assumption is reasonable under the assumptions that the blood vessel wall is thin, the concentration is constant in the blood vessel, and the metabolites are much smaller than the openings in the blood vessels. We then for simplicity assume an even distribution of cells in the tumor space, where the tumor space is divided into two regions for each metabolite. In tumor region A, closest to the capillary, there is an excess of the metabolite and cells only take up some of the available metabolite influx. In tumor region B, further away from the capillary, cells are starving and consume all of the available metabolite influx. It is also assumed that the proportions of different cell types do not vary across the volume, and that cells operate according to the same metabolic regime regardless of distance to the capillary. The latter means that the uptake $u_{i}$ of metabolite $i$ at any distance from the capillary can be expressed as

$$
u_{i}=g u_{r, i}
$$

where $g$ is a proportionality constant and $u_{r, i}$ is the uptake of metabolite $i$ at an arbitrarily chosen distance from the capillary that is the same for all metabolites. The border between region A and B is at different distances from the capillary for different metabolites. It is however important to realize that the metabolites of interest are the growth-limiting metabolites, since the estimate of the upper bounds of other metabolites have no effect on growth. In practice, all limiting metabolites are mainly used for ATP production. To simplify the model, we assume that the border between the regions $A$ and $B$ is at the same place for those metabolites, although this assumption may be slightly violated for some metabolites. To simplify the calculations further, we use the approximation that this border is at the same distance from the capillary $\left(x_{b}\right)$ for all metabolites, since the upper bounds of non-limiting metabolites has little effect on the modeling results. 


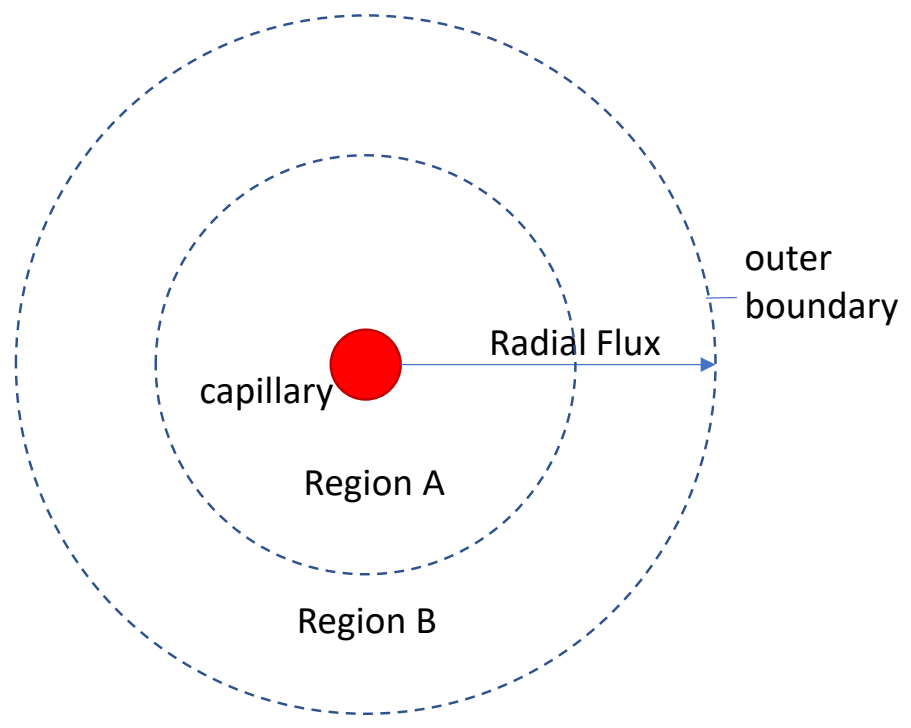

Fig. A. The diffusion model.

Diffusion is governed by Fick's first and second law, under the assumption that we view the tumor as an admixture in a medium, where the metabolite concentrations and gradients are "small" (which is the case here, the concentration is in the scale of around 5,000 $\mu \mathrm{M}$ at the most (for glucose) and the gradients are in investigated at steady state conditions, giving no sharp concentration "edges"). The metabolite flux is determined by Fick's first law:

$\boldsymbol{J}(\boldsymbol{x})=-D \nabla c(\boldsymbol{x})$

where $\mathbf{J}$ is the flux, $D$ the diffusion coefficient, and $\nabla c(\mathbf{x})$ is the metabolite concentration gradient in three-dimensional space (where $\mathbf{x}$ normally is a three-dimensional vector, in our model a twodimensional vector). We can determine $\nabla c(\mathbf{x})$ from boundary conditions and Fick's second law:

$\frac{\partial c(x, t)}{\partial t}=\nabla \cdot(D \nabla c(\boldsymbol{x}, t))$

where $t$ is time and $\nabla \cdot$ is the divergence of the vector field $D \nabla c(\mathbf{x}, t)$. However, Fick's second law assumes that there are no sources or sinks in the simulated volume. In our case, the cells take up metabolites, which will give an additional term on the right-hand side of Eq. 2. In Region A, the uptake rate is constant, and can simply be modeled as $-A$, where $A$ is a constant. In region $B$, we assume that cells take up a proportion of the metabolites that diffuse to the cell surface (with the same proportionality constant). This can be modeled as $-B D c(\mathbf{x})$, where $B$ is a constant. This assumes that for many substrates, such as glucose and amino acids, the most effective transporters have similar $K_{m}$ values. Since we assume that cells behave optimally, they will balance the expression of these transporters to obtain a similar transport capacity for all limiting metabolites, which will give a similar value for the constant $B$ for those metabolites.

If the cells in region $A$ are assumed to behave the same way as cells on the border between region $A$ and region $B$, we can assume that the metabolite uptake is the same for those cells. We can then replace the sink term $-A$ with $-B D c\left(\mathbf{x}_{\mathbf{b}}\right)$, where $x_{b}$ represents the radial position of the border.

For the problem at hand, we focus on steady state conditions, meaning that the left-hand side of Eq. 2 can be set to zero and that the concentration gradient is not dependent on time. Furthermore, for simplicity, we assume that the diffusion constant $D$ doesn't vary within the tumor, which means that $D$ can be moved out of the divergence. We can then rewrite Eq. 2 as 
$0=\nabla \cdot(D \nabla c(\boldsymbol{x}))=D \nabla \cdot(\nabla c(\boldsymbol{x}))=D \Delta c(\boldsymbol{x})$

where $\Delta$ is the Laplace operator. We now add the terms for Region A:

$0=D \Delta c(\boldsymbol{x})-A=D \Delta c(\boldsymbol{x})-B D c\left(\boldsymbol{x}_{\boldsymbol{b}}\right)$

from which the diffusion constant can be removed:

$0=\Delta c(\boldsymbol{x})-B c\left(\boldsymbol{x}_{\boldsymbol{b}}\right)$

Similarly, we add the terms for Region B:

$0=D \Delta c(\boldsymbol{x})-B D c(\boldsymbol{x})(6)$, from which the diffusion constant can be removed:

$0=\Delta c(\boldsymbol{x})-B c(\boldsymbol{x})$

Given our assumptions, the concentration gradients for the limiting metabolites are not dependent on their diffusion coefficients in any of the regions.

To determine the concentration gradient from this equation at maximum metabolite uptake, we need boundary conditions. In our case, Dirichlet boundary conditions are suitable since they specify concentrations, not fluxes, and thereby do not involve the diffusion coefficient. We assume that in steady state there is a fixed concentration of the metabolite just outside the capillary wall, which is proportional to the concentration in the blood $\left(c_{b}\right)$. It is hard to estimate the permeability of the blood vessel, but under the assumption that the blood vessel wall is thin, that the concentration is constant in the blood vessel, and that the metabolites are much smaller than the openings in the blood vessels, this is a reasonable assumption.

The second boundary condition used is that at infinite distance from the blood vessel, the concentration is zero. This is a commonly applied assumption that is required to be able to solve the concentration equation.

To solve the problem, we would need additional data, such as physical distances, etc., which is difficult to acquire. It is however not necessary to solve the problem to estimate the relative maximal fluxes of metabolites - we can directly draw some conclusions from the model given the assumptions: 1) The concentration gradient of a limiting metabolite is not dependent on the diffusion coefficient, since both Eq. 5 and 7 and the boundary conditions are independent of the diffusion coefficient. This means that the gradient $\nabla c(x)$ is approximately the same for all limiting metabolites, given the same concentration in the blood. 2) The concentration gradient $\nabla c(x)$ of a limiting metabolite is approximately proportional to the metabolite concentration in the blood. This follows from that at each boundary condition, the remaining concentration for the limiting metabolites is proportional to the concentration in blood (zero far out and proportional to the blood near the blood vessel), which intuitively means that the concentration gradient divided by the concentration in blood is approximately the same for all limiting metabolites.

Applying Fick's first law, we can thereby model the maximum influx of a limiting metabolite into any point of the tumor as

$J(\boldsymbol{x})=-D \nabla c(\boldsymbol{x})=a D c_{b}$

where the proportionality constant $a$ is the same for all metabolites. For metabolic modeling purposes, the uptake flux of each metabolite can thus be constrained to this value. A low value of $a$ represents the situation at a large distance from the capillary, while a high value gives conditions closer to the blood vessel. This equation can be generalized to 
bioRxiv preprint doi: https://doi.org/10.1101/2022.02.08.479584; this version posted February 10, 2022. The copyright holder for this preprint (which was not certified by peer review) is the author/funder, who has granted bioRxiv a license to display the preprint in perpetuity. It is made available under aCC-BY 4.0 International license.

$U_{i}=a D_{i} c_{b, i}$

where $U_{i}$ is the estimated upper bound for the uptake flux of metabolite $i, D_{i}$ is the diffusion coefficient for metabolite $i$, and $c_{b, i}$ is the concentration of metabolite $i$ in the blood.

There are many uncertainties that will introduce errors in the diffusion model. The model is based on four major assumptions: 1 ) The border between region $A$ and region $B$ is at the same place for all metabolites. 2) The cells have the same relative uptake rate of the growth-limiting metabolites regardless of the value of $a$, which is a simplification of the complex behavior of cells; 3 ) The cells are equally good at taking up different metabolites; and 4) We assume that the blood is constantly replenished and that the concentration of metabolites and oxygen in the blood are unaffected by cellular uptake.

Assumption 1 is likely violated for the limiting metabolites, which can be suspected from the FVA presented in Fig. S3. The violation is not expected to have a large impact on the modeling results but may introduce small errors in the estimated uptake bounds for some metabolites. The error manifests as a small under- or overestimation of the sink terms in Eq. 4 and Eq. 6 for some metabolites, but these errors are deemed small compared to the differences in metabolite concentrations in blood between metabolites.

Assumption 2 is likely violated to a certain extent since different absolute metabolite concentrations are expected to make the cells operate according to different metabolic regimes, which will introduce errors to the estimated uptake constraints. An example of this is the Warburg effect, where cells closer to the capillary are expected to take up a lower fraction of oxygen (compared to other metabolites) than cells further away from the blood vessel.

The third major assumption, where we assume that the cell is equally good at taking up different metabolites, is based on that most metabolites are imported to cells via effective transporters with low $K_{m}$ values. An example is the glucose transporter GLUT1, $K_{m}=1-2 \mathrm{mM}$ for glucose (13), and the glutamine transporter SNAT1, with reported $K m=0.23-0.30 \mathrm{mM}(14)$. It is assumed that differences in $\mathrm{K}_{\mathrm{m}}$ and $\mathrm{k}_{\mathrm{cat}}$ between the transporters can be compensated for by different abundancies of the transporters in the cell membrane. Oxygen is an exception, which behaves very differently from the metabolites. Oxygen easily diffuses into cells through the membrane; the diffusion through the cell membrane is reported to be negligibly lower than in water (15). Furthermore, the diffusion coefficient of oxygen is much higher than for the metabolites, making it more sensitive to errors in the diffusion model. Regardless of these differences, we still modeled oxygen uptake the same way as for the metabolites, although the relative constraint for oxygen uptake likely is less reliable.

Assumption 4, where the blood is expected to be constantly replenished with nutrients and thereby have constant metabolite concentrations throughout the tumor, may not hold. Depletion of oxygen in blood vessels is a well-known phenomenon referred to as acute hypoxia (16), and we can assume that the same effect to a certain extent is available for other metabolites. As long as the limiting metabolites are depleted in an equal way that is not a problem. However, oxygen behaves differently since the concentration is replenished from hemoglobin in the blood, and metabolites with higher diffusion coefficients may be more depleted in the blood. While the differences between most metabolites likely are small, oxygen may stand out together with lipids and albumin.

There are also uncertainties in the diffusion coefficients. For example, the diffusion constant of lipids and albumin are very uncertain, since they may be physically hindered to move in the TME due to their size. However, between metabolites such as glucose and amino acids, the difference in the 
bioRxiv preprint doi: https://doi org/10.1101/2022.02.08.479584: this version posted February 10,2022 . The copyright holder for this preprint (which was not certified by peer review) is the author/funder, who has granted bioRxiv a license to display the preprint in perpetuity. It is made available under aCC-BY 4.0 International license.

diffusion coefficients is modest, and measurement errors there are not expected to have a large impact on the modeling results.

Taking all error sources into consideration, the uptake constraints are to be seen as an approximation of the true value. The uptake constraints for oxygen and lipids are expected to be more uncertain than the rest. Oxygen levels are however not that critical for the modeling results, we only need the oxygen levels to be low, which is a well-known fact in tumors. Results regarding lipids, however, are more uncertain and should be interpreted with care. In general, the diffusion model is also more reliable for higher values of a, since a smaller part of the regions where cells take up metabolites have been passed, reducing the errors introduced by some of the assumptions. 


\section{Supplementary Note 3 - metabolite concentrations in blood}

Since the diffusion model requires concentrations of metabolites in blood, we retrieved blood plasma measurements from several sources to form a collection of 69 metabolites with associated concentration values. The metabolites were filtered on the criteria that the metabolite must be represented in the model and have a blood plasma concentration above $1 \mu \mathrm{M}$. Specifically, we downloaded the average concentration of 94 polar metabolites in blood plasma from 8,413 healthy patients in a Japanese cohort (5), of which 64 passed the filtering criteria, which also included removal of lipids. In addition to these metabolites, we also allowed for uptake of albumin, since cancer cells are known to take up albumin as a source of amino acids, at a plasma mass concentration of $40 \mathrm{~g} / \mathrm{l}(17)$.

Due to the high number of lipid species we grouped the lipids into two categories: sterols and other lipids, where the latter included fatty acyls, glycerolipids, glycerophospholipids, and sphingolipids. Sterols were represented by cholesterol in the model, while the other lipids were assumed to eventually be converted to a composition of fatty acids defined by the metabolite "NEFA blood pool in", which is predefined in Human1 to match the composition in blood plasma. Lipid concentrations in blood plasma were downloaded from literature (18) and summed up to form mass concentrations in blood plasma for our two lipid groups. The average molecular weight of the "NEFA blood pool in" was calculated from its composition, and the mass concentrations were then converted to blood plasma concentrations for cholesterol and "NEFA blood pool in".

Estimation of the oxygen concentration is a special case since the concentration for the diffusion model should be that of free oxygen and not include oxygen bound to hemoglobin. The free oxygen has been estimated to only be around 1-2 \% of the total oxygen in blood, at a concentration of around $100 \mu \mathrm{M}(4)$. In addition, any remaining metabolites that are essential for growth were added either unbounded (for metabolites that do not actively contribute to growth, such as water etc.) or with an upper bound of ten times the lowest upper bound present for the other metabolites, which is a level tested to be sufficient but not high enough to have a large impact on growth.

To test the validity of the metabolite concentration values, we downloaded and curated blood plasma concentration values from the human metabolome database (v. 4.0), HMDB (1,2), which contains concentration data from a large collection of studies. The metabolite concentrations in our metabolite collection were in good agreement with HMDB for the metabolites present in both sources (Fig. S1). In addition, we scanned HMDB for metabolites that were not present in our metabolite collection, yielding a collection of additional metabolite candidates (Table S1) and a list of metabolites that could not be mapped to the model (Table S2), both only containing metabolites with modest concentrations. To reduce the complexity of the model we decided not to include any of the new candidates since they were not deemed important and concluded that none of the unmapped metabolites would have a large effect on our modeling outcome. Our collection of metabolites with associated concentrations was hence deemed suitable for use with our model. The metabolite concentrations are available in Table S3. 


\section{Supplementary Note 4 - metabolite diffusion coefficients in tumors}

The diffusion model requires the diffusion coefficients for the metabolites in the model. Reliable diffusion coefficients for the tumor microenvironment are hard to come by, and it is difficult to know how diffusion coefficients differ between different fluids. Some values are available for blood plasma (19), although these were based on nuclear magnetic resonance (NMR) measured in two dimensions, which has been reported to be less reliable (20). We settled for using diffusion coefficients measured in mouse seminal fluid for 16 of the polar metabolites in our metabolite collection (20). We predicted the diffusion coefficients for the remaining small polar metabolites based on a linear model based on molecular mass (Fig. S2), which is reasonable as long as the masses are within a reasonably small range (21). The diffusion coefficients for albumin (22) and oxygen (23) were collected separately from the literature. Lipids are not soluble in water and are therefore transported together with albumin or a lipoprotein, or potentially as droplets. These are large particles that do not diffuse well, and we modeled the diffusion of these particles by using the diffusion coefficient of albumin for all lipids. The metabolite concentrations and diffusion coefficients are available in Table S3. 


\section{Supplementary Note 5 - NADH/FADH 2 in amino acid metabolism}

Amino acid metabolism in the genome-scale model is tightly connected to the effects of $\mathrm{NADH} / \mathrm{FADH} 2$ production in the model. In normal conditions, these substrates can be oxidized by the electron transport chain to yield ATP. However, for fast growing cells with sufficient access to nutrients and oxygen, enzymatic capacity becomes limiting for growth and the model compensates by reducing its use of the ETC. The ETC complexes, of particular interest complex I, are large and slow and there are other strategies that can yield more ATP per enzyme usage. While aerobic glycolysis is the main alternative for producing ATP, the TCA cycle also remains an option, but can only be used if the NADH/FADH2 generated in the cycle can be oxidized. Thus, if the cell can either generate less NADH/FADH2 while running the TCA cycle or use alternative pathways to oxidize these substrates, the flux through the TCA cycle can be increased, contributing to the total ATP production. The NADH/FADH2 ratio is also important, since NADH requires the use of complex I while FADH2 does not, and the enzymatic cost per ATP produced is higher if complex I is used. However, the oxidation of NADH/FADH2 by the ETC under hypoxic, nutrient-deprived conditions is limited by oxygen availability rather than enzyme usage, so it becomes important to get as much ATP as possible out of each oxygen molecule. Since the oxidation of FADH2 is coupled to the reduction of ubiquinone to ubiquinol without generating any proton motive force, the ratio of NADH to FADH2 processed by the ETC should be as high as possible. Depletion of NADH under such conditions may therefore have a negative effect on ATP production, and it may be beneficial to generate NADH by other means than running the TCA cycle to avoid generation of FADH2. 


\section{References}

1. Psychogios N, Hau DD, Peng J, Guo AC, Mandal R, Bouatra S, et al. The Human Serum Metabolome. PLOS ONE. 2011 Feb;6(2):e16957.

2. Wishart DS, Feunang YD, Marcu A, Guo AC, Liang K, Vázquez-Fresno R, et al. HMDB 4.0: the human metabolome database for 2018. Nucleic Acids Res. 2018 Jan 4;46(D1):D608-17.

3. Akinci G, Topaloglu H, Demir T, Danyeli AE, Talim B, Keskin FE, et al. Clinical spectra of neuromuscular manifestations in patients with lipodystrophy: A multicenter study. Neuromuscul Disord. 2017 Oct 1;27(10):923-30.

4. Siggaard-andersen $\mathrm{O}, \mathrm{G} \varnothing$ thgen $\mathrm{IH}$, Wimberley PD, Fogh-andersen $\mathrm{N}$. The oxygen status of the arterial blood revised: Relevant oxygen parameters for monitoring the arterial oxygen availability. Scand J Clin Lab Invest. 1990 Jan 1;50(sup203):17-28.

5. Harada S, Hirayama A, Chan Q, Kurihara A, Fukai K, lida M, et al. Reliability of plasma polar metabolite concentrations in a large-scale cohort study using capillary electrophoresis-mass spectrometry. PLOS ONE. 2018 Jan;13(1):e0191230.

6. Robinson JL, Kocabaş P, Wang H, Cholley P-E, Cook D, Nilsson A, et al. An atlas of human metabolism. Sci Signal [Internet]. 2020 Mar 24 [cited 2020 Mar 28];13(624). Available from: https://stke.sciencemag.org/content/13/624/eaaz1482

7. Domenzain I, Sánchez B, Anton M, Kerkhoven EJ, Millán-Oropeza A, Henry C, et al. Reconstruction of a catalogue of genome-scale metabolic models with enzymatic constraints using GECKO 2.0. bioRxiv. 2021 Mar 5;2021.03.05.433259.

8. Bekiaris PS, Klamt S. Automatic construction of metabolic models with enzyme constraints. BMC Bioinformatics. 2020 Jan 14;21(1):19.

9. Sage RF. Variation in the kcat of Rubisco in C3 and C4 plants and some implications for photosynthetic performance at high and low temperature. J Exp Bot. 2002 Apr 1;53(369):60920.

10. Zielinski DC, Jamshidi N, Corbett AJ, Bordbar A, Thomas A, Palsson BO. Systems biology analysis of drivers underlying hallmarks of cancer cell metabolism. Sci Rep. 2017 Jan 25;7(1):41241.

11. Jain M, Nilsson R, Sharma S, Madhusudhan N, Kitami T, Souza AL, et al. Metabolite profiling identifies a key role for glycine in rapid cancer cell proliferation. Science. 2012 May 25;336(6084):1040-4.

12. Nilsson A, Haanstra JR, Teusink B, Nielsen J. Metabolite Depletion Affects Flux Profiling of Cell Lines. Trends Biochem Sci. 2018 Jun 1;43(6):395-7.

13. Ancey P-B, Contat C, Meylan E. Glucose transporters in cancer - from tumor cells to the tumor microenvironment. FEBS J. 2018;285(16):2926-43.

14. Leke R, Schousboe A. The Glutamine Transporters and Their Role in the Glutamate/GABAGlutamine Cycle. In: Schousboe A, Sonnewald U, editors. The Glutamate/GABA-Glutamine Cycle: Amino Acid Neurotransmitter Homeostasis [Internet]. Cham: Springer International 
bioRxiv preprint doi: https://doi org/10.1101/2022 $02.08 .479584 \cdot$ this version posted February 10,2022 . The copyright holder for this preprint (which was not certified by peer review) is the author/funder, who has granted bioRxiv a license to display the preprint in perpetuity. It is made available under aCC-BY 4.0 International license.

Publishing; 2016 [cited 2021 May 25]. p. 223-57. (Advances in Neurobiology). Available from: https://doi.org/10.1007/978-3-319-45096-4_8

15. Is the mammalian cell plasma membrane a barrier to oxygen transport? J Gen Physiol. 1992 Jul 1;100(1):69-87.

16. Fleming IN, Manavaki R, Blower PJ, West C, Williams KJ, Harris AL, et al. Imaging tumour hypoxia with positron emission tomography. Br J Cancer. 2015 Jan;112(2):238-50.

17. Hoogenboezem EN, Duvall CL. Harnessing Albumin as a Carrier for Cancer Therapies. Adv Drug Deliv Rev. 2018 May;130:73-89.

18. Quehenberger O, Armando AM, Brown AH, Milne SB, Myers DS, Merrill AH, et al. Lipidomics reveals a remarkable diversity of lipids in human plasma1[S]. J Lipid Res. 2010 Nov 1;51(11):3299-305.

19. Liu M, Nicholson JK, Parkinson JA, Lindon JC. Measurement of Biomolecular Diffusion Coefficients in Blood Plasma Using Two-Dimensional 1H-1H Diffusion-Edited Total-Correlation NMR Spectroscopy. Anal Chem. 1997 Apr 1;69(8):1504-9.

20. Zhang X, Li C-G, Ye C-H, Liu M-L. Determination of Molecular Self-Diffusion Coefficient Using Multiple Spin-Echo NMR Spectroscopy with Removal of Convection and Background Gradient Artifacts. Anal Chem. 2001 Aug 1;73(15):3528-34.

21. Valencia DP, González FJ. Estimation of diffusion coefficients by using a linear correlation between the diffusion coefficient and molecular weight. J Electroanal Chem. 2012 Aug 1;681:121-6.

22. Chary SR, Jain RK. Direct measurement of interstitial convection and diffusion of albumin in normal and neoplastic tissues by fluorescence photobleaching. Proc Natl Acad Sci. 1989 Jul 1;86(14):5385-9.

23. Goldstick TK, Ciuryla VT, Zuckerman L. Diffusion of oxygen in plasma and blood. Adv Exp Med Biol. 1976;75:183-90. 